\title{
Um Instrumento para Avaliação de Mecanismos de Transparência em Portais de Ecossistema de Software
}

\section{Title: An Instrument for the Evaluation of Transparency Mechanisms in Software Ecosystem Portals}

\author{
Alexandre Inácio Meireles ${ }^{1}$, Rodrigo Pereira dos Santos' ${ }^{1}$, Claudia Cappelli ${ }^{2}$ \\ Programa de Pós-Graduação em Informática \\ Universidade Federal do Estado do Rio de Janeiro (PPGI/UNIRIO) \\ Rio de Janeiro, Brasil \\ 2Programa de Pós-Graduação em Informática \\ Universidade Federal do Rio de Janeiro (PPGI/UFRJ) \\ Rio de Janeiro, Brasil \\ \{alexandre.meireles, rps\}@uniriotec.br, claudia.cappelli@gmail.com
}

\begin{abstract}
Companies have opened up their software/systems architectures to enable collaboration from external developers and users, forming software ecosystems (SECO). In this context, social web support environments, such as web portals, are fundamental to enable coordination, collaboration and interaction within a SECO. One of the challenges faced is to assess the transparency of these portals in order to improve the experience of developers. This work aims to develop a questionnaire that allows evaluating transparency in SECO portals according to the ecosystem objectives. To do so, an exploratory study was carried out in two SECO portals. Next, we performed a systematic mapping study regarding how transparency and its characteristics have been investigated in the SECO literature. The first version of the artifact was evaluated with ten SECO experts and allowed us to generate the Instrument for Assessing Transparency in SECO Portals (ITRANSPE). Next, a new study was executed with developers and the final version of the instrument for evaluating contributions of transparency characteristics and proposing suggestions, if any of them are not present in SECO portals.
\end{abstract}

Keywords. Software Ecosystems; Transparency; Social Web; Assessment.

Resumo. Empresas têm aberto as suas arquiteturas de software/sistemas para permitir a colaboração entre desenvolvedores externos e usuários, formando ecossistemas de software (ECOS). Nesse contexto, os ambientes de suporte a web social, como portais web, são fundamentais para permitir coordenação, colaboração e interação em um ECOS. Um dos desafios enfrentados está em avaliar o grau de transparência desses portais a fim de melhorar a experiência de desenvolvedores. Este trabalho se propõe a construir um artefato que possa ser usado para avaliar a transparência nos portais de ECOS. Para a construção deste artefato, foi realizado um estudo exploratório em dois portais, seguido da realização de um mapeamento sistemático para identificar trabalhos sobre 
transparência e suas características aplicadas a ECOS. A primeira versão do artefato foi avaliada a partir da opinião de dez especialistas em ECOS e derivou o Instrumento para Avaliação da Transparência em Portais de ECOS (ITRANSPE), que foi avaliado em um estudo com desenvolvedores. Como resultado, foi consolidada a versão final do ITRANSPE, que avalia contribuições das características da transparência e propõe sugestões, caso alguma delas não esteja presente em portais de ECOS.

Palavras-Chave. Ecossistemas de Software; Transparência; Web Social; Avaliação.

\section{Introdução}

Com o surgimento de abordagens de desenvolvimento de software mais modernas, manter uma arquitetura de software/sistema totalmente internalizadas à organização tem sido um grande desafio para as empresas (BARBOSA et al., 2013). Por esta razão, as empresas têm aberto suas arquiteturas para permitir a colaboração de desenvolvedores externos e usuários no desenvolvimento de seus componentes, permitindo que interajam com seus sistemas (CAMPBELL et al., 2010). Surge assim um novo cenário de desenvolvimento, em que várias soluções, empresas e desenvolvedores colaboram em uma plataforma de software comum, formando o que tem sido chamado de Ecossistema de Software (ECOS) (JANSEN et al., 2009). Neste contexto, os ambientes de suporte a web social (e.g., portais web) têm sido fundamentais para permitir a colaboração e interação em ecossistemas, denominados portais de ECOS.

No entanto, a criação destes ambientes chama atenção para outros pontos que se tornam vitais, considerando a quantidade de atores: os riscos de um ambiente colaborativo, o volume de informações exponencialmente crescente, entre outros. Neste contexto, o conceito de transparência passa a se tornar peça fundamental, indicando que características como acessibilidade, usabilidade, qualidade da informação, entendimento e auditabilidade devem ser previamente definidas e implementadas nestes ambientes, conforme Leite e Cappelli (2010). A transparência pode ser tratada como um requisito não funcional nos sistemas de informação que constituem a plataforma do ECOS, pois permite que todos os interessados se tornem responsáveis por este requisito e avaliem a sua confiabilidade por meio de ações de divulgação institucional relevantes (SCHNACKENBERG \& TOMLINSON, 2014). Dessa forma, a transparência serve como um mecanismo de coordenação chave para os membros do ECOS, pois a informação disponível permite que eles estejam conscientes da evolução e das atividades de desenvolvimento de software (GUTWIN et al., 2004).

Leite e Cappelli (2010) definem o escopo de transparência em três níveis: a transparência organizacional, a transparência direcionada e a transparência social. Cada um deles tem um foco específico: a primeira foca nos interessados, a segunda foca nos consumidores e a terceira foca nos cidadãos. Para tal, os principais interessados em um ECOS (ou seus membros) devem definir o escopo do seu interesse e o nível de transparência que desejam ver no ECOS, ou seja, os tipos e características (SANTOS et al., 2016). Nesse contexto, a disponibilidade de qualquer tipo de informação sobre os aspectos do processo de desenvolvimento e suas atividades (e.g., fonte, código, documentação de design, rastreamento de defeitos e lista de discussão) é a ideia básica por trás da transparência. Em outras palavras, é um princípio fundamental de desenvolvimento aberto desde os primeiros dias (CATALDO \& HERBLSLEB, 2010). 
A transparência das plataformas tem recebido pouca atenção da comunidade cientifica, o que é intrigante, uma vez que os desenvolvedores geralmente começam o desenvolvimento escolhendo uma plataforma, que satisfaça grandes partes das funcionalidades requeridas pelos desenvolvedores (JANSEN et al., 2013). Nesse contexto, a falta de transparência é uma queixa frequente de desenvolvedores em ECOS (JANSEN et al., 2013), ao passo que esse requisito é uma característica fundamental para ECOS (FRANCO-BEDOYA et al., 2014). Logo, a questão de pesquisa deste trabalho é: "Como mecanismos que permitem a avaliação de transparência dos portais dos ECOS podem melhorar a relação dos desenvolvedores com esses portais?". Nessa direção, este trabalho se propõe a construir um artefato que possa ser usado para avaliar a transparência nos portais de ECOS. Para a construção deste artefato, foi realizado um estudo exploratório em dois portais e um mapeamento sistemático para identificar trabalhos sobre transparência e suas características aplicadas em ECOS. Nesse sentido este trabalho começou com a aplicação de um questionário voltado para transparência em sites, evoluiu-se para um artefato derivado para portais de ECOS e, como versão final, gerouse um instrumento para avaliação de mecanismos de transparência em portais de ECOS.

A primeira versão do artefato proposto foi avaliada por dez especialistas em ECOS e viabilizou a produção do Instrumento para Avaliação da Transparência em Portais de ECOS (ITRANSPE), sobre o qual foi executado um estudo com desenvolvedores, a fim de que eles aplicassem o instrumento em algum portal de ECOS e opinassem sobre dois aspectos: facilidade de uso e utilidade. Como resultado, foi consolidada a versão final do ITRANSPE, que avalia contribuições das características da transparência e propõe sugestões, caso alguma característica não esteja presente em portais de ECOS. A fim de discorrer sobre a pesquisa realizada, além desta seção introdutória, este artigo está organizado da seguinte forma: a Seção 2 apresenta a fundamentação teórica; na Seção 3, discutimos o método de pesquisa adotado; na Seção 4, o mapeamento sistemático é apresentado; a Seção 5 introduz o ITRANSPE; na Seção 6, a avaliação do instrumento é explicada; por fim, a Seção 7 conclui o artigo com as considerações finais.

\section{Fundamentação Teórica}

Essa seção apresenta a fundamentação teórica relativa a como transparência e o desenvolvimento de software em ECOS têm sido explorados na literatura. Neste contexto, o desenvolvimento de software requer pensar mais cuidadosamente as plataformas que vão apoiá-lo bem como as suas redes de artefatos e envolvidos, isto é, relacionamentos de conectividade e de dependência entre os produtos e as organizações. Tais relações envolvem fornecedores, distribuidores, organizações terceirizadas, desenvolvedores de produtos e de serviços relacionados e uma gama de outras organizações e clientes que afetam (e são afetados por) esse cenário (JANSEN et al., 2009).

Por sua vez, segundo Bosch (2009), esse cenário demanda engenheiros de software com a habilidade de abstrair a complexidade do sistema como um todo. Neste caso, o sistema de software representa uma combinação de software, hardware e "peopleware" constituída sobre um ambiente comum, isto é, uma plataforma. Pode-se identificar uma tendência: o nascimento, desenvolvimento, amadurecimento e eventual "morte" ou transformação de plataformas levam à "desconstrução" da visão tradicional da engenharia de software. Privilegia-se uma nova visão, que contempla a colaboração e a interoperabilidade entre os atores (CAMPBELL \& AHMED, 2010). Na década de 2000, 
essas estruturas, conhecidas como ECOS (do inglês, software ecosystems ou SECO) foram alvos de pesquisa na área de Engenharia de Software.

Inspirados nos ecossistemas biológicos, sociais e de negócios, ECOS favorece o uso de analogias para aplicar novas visões e abstrações sobre os desafios da indústria de software (JANSEN \& CUSUMANO, 2012). Ao reunir diversos projetos em torno de uma tecnologia de software central (plataforma de ECOS), esses modelos têm permitido o desenvolvimento de plataformas globalizadas, de larga escala e longo prazo (MANIKAS \& HANSEN, 2013). Tais plataformas originam sistemas mais complexos que integram uma rede de diversos atores e artefatos, mesmo externos (BOSCH, 2009).

Paralelamente, transparência tem sido uma preocupação crítica para a sociedade moderna (HOLZNER \& HOLZNER, 2006) e um conceito amplamente difundido, todavia com um grande espectro de interpretações e definições (CAPPELLI et al., 2013). Lord et al. (2007) estabelecem transparência como condição para que as informações relativas a prioridades, capacidades e comportamento estejam amplamente disponíveis. A geração de informação nas organizações e processos organizacionais é, em sua grande parte, realizada pelo uso de software, tornando-se necessária a extensão do conceito de transparência ao software e processos de desenvolvimento (SANTOS et al., 2016). Nesse sentido, Cappelli (2009) propôs um questionário para avaliação de transparência em sites em geral, como uma iniciativa para apoiar a operacionalização de avaliações no contexto de Engenharia de Software e Sistemas de Informação.

No contexto de um ECOS, a transparência permite aos interessados aprender e entender seus elementos, bem como os processos usados para desenvolver software em suas plataformas (CATALDO \& HERBSLEB, 2010). Portanto, a ausência da devida transparência do que cada interessado tem como política de convivência, isto é, como está disposto a interagir/comunicar, se torna um grande obstáculo para a construção de sistemas nesse contexto (SANTOS et al., 2016). Logo, um dos principais benefícios da transparência é o seu papel central como mecanismo de coordenação para os membros do ECOS, porque a disponibilidade das informações permitiria aos interessados entenderem a evolução das atividades no ECOS (CATALDO \& HERBSLEB, 2010).

Os padrões de desenvolvimento atuais têm buscado promover a disponibilização das informações em formatos abertos e acessíveis, a fim de possibilitar a reutilização e a sua interligação com informação de outras fontes, gerando novos significados (SANTOS et al., 2016). Isso tem sido possível com o uso do conceito de Dados Governamentais Abertos (GERMANO \& TAKAOKA, 2012), que tem relação com a transparência (CRUZ et al., 2016). Considerando essa e outras necessidades, Cappelli (2009) busca definir transparência a partir de um conjunto de conceitos inter-relacionados, cujas informações devem satisfazer as condições de serem: completas, objetivas, confiáveis, corretas, íntegras, consistentes, precisas, acessíveis, compreensíveis e livres para acesso.

\section{Método da Pesquisa}

Essa seção explica o método de pesquisa utilizado, de modo a explicar como o trabalho foi estruturado e como os estudos foram conduzidos, bem como a sua motivação. Considerando os objetivos e os principais conceitos envolvidos nessa pesquisa, o uso de métodos qualitativos se mostrou a melhor estratégia para a condução do trabalho. Métodos qualitativos contam com estratégias que permitem investigar fenômenos dentro de um contexto real e são úteis especialmente quando os limites entre fenômenos e 
contextos não são aparentes. São indicados quando se deseja estudar um fenômeno particular em profundidade ou para pesquisas exploratórias, em que um fenômeno é considerado emergente, não totalmente compreendido ou pesquisado (RECKER, 2012).

Seguindo essa estratégia, na primeira etapa, realizou-se um estudo exploratório em dois portais de ECOS: o Portal do Software Público (SPB) e o Portal da Apple Store. Esses portais foram escolhidos considerando a perspectiva de desenvolvedores que os utilizam para desenvolver software e aplicativos. No estudo conduzido, foi aplicado o questionário para avaliação de transparência em sites desenvolvido por Cappelli (2009) e aprimorado por Carvalho et al. (2017), a partir do qual se buscou responder se cada questão existente para avaliar transparência em sites era aplicável a esses portais de ECOS e se determinada característica da transparência estava ou não presente. A motivação principal foi a oportunidade de melhoria na transparência nesses portais a partir de um instrumento consolidado e genérico para sites, uma vez que um portal de ECOS é um site agregado com mecanismos que apoiam os desenvolvedores a buscarem informações. Detalhes deste estudo foram publicados anteriormente (MEIRELES et al., 2017ab).

$\mathrm{Na}$ segunda etapa, contemplou-se a realização de um mapeamento sistemático da literatura, que teve como objetivo identificar trabalhos sobre transparência e suas características aplicadas especificamente em ECOS, a fim de permitir a construção de um instrumento de avaliação que levasse em consideração as particularidades desse contexto. Dessa forma, este mapeamento focou o estado da arte em transparência em ECOS, motivado pelo estudo de Santos et al. (2016).

A partir dos resultados das etapas anteriores, na terceira etapa, adaptou-se o questionário de avaliação de transparência em sites para que pudesse então avaliar transparência em portais de ECOS. O questionário adaptado foi submetido para uma avaliação com dez especialistas em ECOS visando avaliar a sua efetividade.

$\mathrm{Na}$ quarta etapa, foram feitas as alterações sugeridas pelos especialistas e evoluiuse o questionário para um instrumento que também retorna sugestões de melhoria de transparência para portais de ECOS.

Em seguida, na quinta etapa, o instrumento foi submetido a uma avaliação com desenvolvedores em plataformas de ECOS a fim de avaliar aspectos de facilidade de uso e de utilidade. Por fim, gerou-se a versão final do instrumento, que avalia contribuições das características da transparência e propõe sugestões, caso alguma delas não esteja presente em portais de ECOS.

\section{Mapeamento Sistemático}

Esta seção trata do mapeamento sistemático da literatura realizado a partir dos resultados do estudo exploratório. O objetivo do mapeamento foi identificar os principais trabalhos sobre transparência em ECOS e agregar as contribuições para esta pesquisa. Isso foi motivado pelo fato de que, durante o desenvolvimento deste trabalho, foi necessário identificar e analisar outros trabalhos que têm discutido transparência em ECOS. O planejamento e a execução do mapeamento seguiram as diretrizes largamente utilizadas nas áreas de Engenharia de Software e Sistemas de Informação (KITCHENHAM \& CHARTERS 2007). 


\subsection{Questões de Pesquisa}

Uma abordagem para a formulação das questões de pesquisa é utilizar os critérios especificados pelo PICOC (KITCHENHAM \& CHARTERS 2007), que investiga as estruturas das perguntas de acordo com cinco atributos: população, intervenção, comparação, resultados e contexto. No entanto, como o foco deste mapeamento da literatura foi caracterizar resultados, os atributos de comparação e intervenção não foram utilizados e, portanto, apenas atributos como a população e resultado (PO) foram considerados, como acontece em estudos desta natureza. A Tabela 1 mostra os detalhes.

Tabela 1. Questões de investigação estruturadas pelos critérios do PIO

\begin{tabular}{|l|l|}
\hline População & Ecossistemas de Software \\
\hline Resultado & Transparência \\
\hline
\end{tabular}

A questão de pesquisa é a seguinte: "Como tem sido pesquisada a transparência em ECOS?”. A partir dessa questão, foram definidas quatro sub-questões (Sub-Qs):

- Sub-Q1: Que modelos, métodos e técnicas têm sido utilizados para avaliar a transparência em ECOS?

- Sub-Q2: Quais as principais características que contribuem para a transparência em ECOS?

- Sub-Q3: O que se sabe atualmente sobre os benefícios, desafios e limitações sobre transparência em ECOS?

- Sub-Q4: Quais as implicações dos estudos sobre transparência em ECOS?

\subsection{Termos de Busca}

Os termos de pesquisa foram reunidos em uma string de busca, que foi utilizada no processo de pesquisa. Os termos estão escritos em inglês, uma vez que este idioma tem sido adotado pela grande maioria das conferências e periódicos internacionais relacionados ao tema da pesquisa. A seguir, apresentamos a string de busca, tendo sido ainda utilizado um recurso oferecido pelas fontes de busca que delimita a área de pesquisa para Ciência da Computação.

\section{("software ecosystem*" OR "digital ecosystem*")}

\section{AND (Transparenc*)}

A busca foi realizada nas bibliotecas digitais Scopus, Engineering Village e ACM Digital Library, pois as três bibliotecas digitais possuem um bom funcionamento e abrangência de suas máquinas de busca, conforme evidencioado no trabalho de Nitze et al. (2014). Kitchenham \& Charters (2007) afirmam que a Scopus é a maior base de dados de indexação de resumos e citações. Por sua vez, a ACM Digital Library também indexa algumas publicações da Springer Link e Science Direct.

Para avaliar a qualidade e abrangência da string de busca, foi realizada uma pesquisa inicial, na qual foram definidos dois artigos de controle: (CATALDO \& HERBSLEB, 2010) e (JANSEN et al., 2012). Após a execução da string de busca nas bibliotecas digitais, verificou-se que os dois artigos de controle estavam entre as publicações retornadas nas bibliotecas digitais Scopus e Engineering Village, ao passo que o trabalho de Cataldo \& Herbsleb (2010) retornou também na ACM Digital Library. 


\subsection{Execução}

O mapeamento sistemático foi conduzido por três pesquisadores e o processo de seleção de estudos foi sistematizado seguindo três etapas: (1) execução da busca; (2) primeiro filtro; e (3) segundo filtro. Durante a execução de busca, foram realizados quatro refinamentos na string de busca para obter melhores resultados. Não houve restrição no período, mas a busca do último refinamento da string ocorreu em maio de 2018. Utilizouse a string de busca nas fontes selecionadas e armazenou-se o conjunto de referências recuperadas em planilhas eletrônicas.

A fim de selecionar os estudos que melhor respondessem as questões de pesquisa, Kitchenham \& Charters (2007) sugerem a definição de critérios de inclusão e exclusão para os estudos que são retornados pela string de busca. Na Tabela 2, encontram-se os critérios de seleção.

Tabela 2. Critérios de Seleção

\begin{tabular}{|c|c|l|}
\cline { 2 - 3 } \multicolumn{1}{c|}{} & Código & \multicolumn{1}{c|}{ Descrição } \\
\hline $\begin{array}{c}\text { Critérios } \\
\text { de } \\
\text { Inclusão }\end{array}$ & Cl01 & O artigo investiga e analisa a transparência em ECOS. \\
\hline \multirow{2}{*}{$\begin{array}{c}\text { Critérios } \\
\text { de }\end{array}$} & CE01 & O artigo não analisa em detalhe a transparência em ECOS. \\
\cline { 2 - 3 } Exclusão & CE02 & Artigos duplicados. \\
\cline { 2 - 3 } & CE03 & Falta de disponibilidade do artigo para download. \\
\hline
\end{tabular}

No primeiro filtro, foram analisados os artigos retornados na busca por meio dos critérios de inclusão e exclusão, pela leitura dos títulos e resumos dos artigos. No segundo filtro, foi realizada a leitura completa dos artigos incluídos no primeiro filtro e analisados novamente por meio dos critérios de inclusão e exclusão. Foram excluídos os artigos cujo conteúdo não atendia aos critérios de seleção, justificando-se a decisão. Os resultados quantitativos obtidos em cada etapa são resumidos na Tabela 3.

Tabela 3. Processo de Seleção de Publicação

\begin{tabular}{|c|c|c|c|c|}
\cline { 2 - 5 } \multicolumn{1}{c|}{} & $\begin{array}{c}\text { Resultado } \\
\text { da Busca }\end{array}$ & $\begin{array}{c}\text { Remoção de } \\
\text { Duplicados }\end{array}$ & $1^{\circ}$ Filtro & $2^{\circ}$ Filtro \\
\hline ACM & $\mathbf{3}$ & $\mathbf{3}$ & $\mathbf{3}$ & $\mathbf{3}$ \\
\hline $\begin{array}{c}\text { Engineering } \\
\text { Village }\end{array}$ & 16 & 12 & 11 & 9 \\
\hline Scopus & 7 & 0 & 0 & 0 \\
\hline
\end{tabular}

Durante a execução da busca, foram retornados 26 artigos nas fontes de busca. Em seguida, foram removidos os artigos duplicados. O primeiro filtro foi realizado por um pesquisador, que analisou o resumo e a conclusão de cada artigo, supervisionado por outro pesquisador. Seguiu-se assim para o segundo filtro, em que se analisou todo o artigo, buscando se o mesmo responde à questão de pesquisa, gerando um conjunto de 12 artigos incluídos efetivamente no estudo. Por fim, foram analisados os artigos incluídos, buscando responder às questões de pesquisa do estudo, a partir da supervisão do terceiro pesquisador. A lista de todas as publicações extraídas está disponível no Apêndice I.

Das 14 publicações excluídas, dez eram repetidas e uma não possuía autor. Entre outras três, uma foi excluída na aplicação do primeiro filtro (KRUIZE et al., 2014), pois tratava da descrição de um modelo de informação agrícola (não explorava transparência 
em ECOS); as outras duas foram excluídas ao se aplicar o segundo filtro (CASTRO et al. 2013; WNUK et al., 2014), pois, na leitura dos dois artigos, foi identificado que não tratavam de transparência em ECOS.

\subsection{Resultados}

No primeiro momento, os resultados do mapeamento sistemático foram analisados quantitativamente em relação aos veículos e ao ano de publicação. Em relação aos veículos de publicação, $42 \%$ dos artigos foram publicados em revistas ou periódicos, ao passo que $58 \%$ foram publicados em conferências. No que se refere ao período de publicação, a Figura 1 mostra a distribuição de publicações por ano. Desde 2010, transparência em ECOS vem sendo relatadas em publicações científicas.

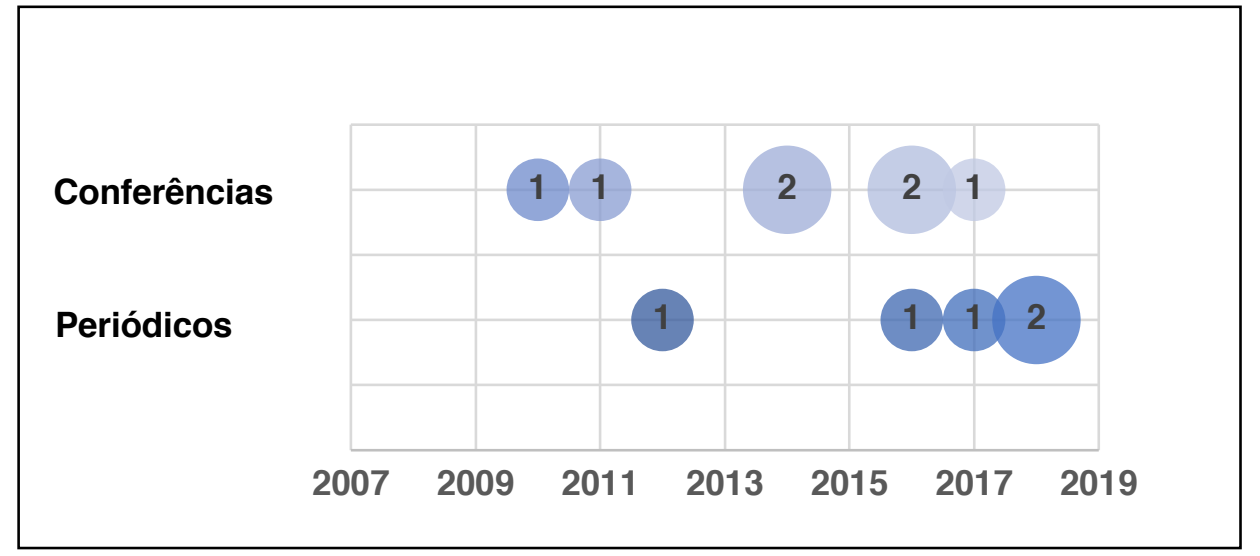

Figura 1. Distribuição das publicações por ano e por tipo de publicação

\subsubsection{Sub-Q1: Que modelos, métodos e técnicas têm sido utilizados para avaliar a transparência em ECOS?}

Foram identificados três modelos de avaliação de transparência em ECOS, conforme apresentado na Tabela 4. O trabalho de Cataldo \& Herbsleb (2010) analisa o ambiente ECOS sobre o princípio de transparência e modularidade, explicando seus benefícios e desafios, além de introduzir o conceito de interface translúcida como forma de superá-los nas dimensões técnica e socio-organizacional. A fim de enfrentar esses desafios, os autores buscam definições do conceito de interface translúcida na literatura e expõem a interseção de trabalhos correlatos objetivando aumentar a visibilidade de informações específicas ou comportamentos, enquanto oculta outros. Na conclusão, os autores apresentam o conceito de interface translúcida como um mecanismo para permitir a colaboração escalável em ECOS, além de apresentarem como futuras pesquisas de interfaces translúcidas: medições e extensões; modelagem de fatores de sucessos em ECOS; e ferramentas colaborativas.

O trabalho de Fahl et al. (2014) apresenta o framework Aplication Transparency (AT), que visa defender usuários de ataques maliciosos. Foi feito um intenso estudo com instalações de aplicativos no mundo real e foi detectado que o AT pode efetivamente proteger contra-ataques maliciosos. O trabalho apresenta os pontos vulneráveis na disponibilização de aplicativos por meio do Google Play, explica que o framework AT se deriva do Certificate Transparency (CT) e demonstra o seu diferencial: fornecer prevenção síncrona em vez de notificação retroativa, garantido que os desenvolvedores não vão ter seus aplicativos alterados ou distribuídos sem o seu conhecimento. Como 
conclusão, os autores mostraram o resultado do uso do AT no estudo de casos reais, apresentando paralelos entre mercados de aplicativos e ECOS que já foram vítimas de ataques. Nesse sentido, discutem que o AT é mais fácil de implantar por ser um mecanismo eficaz para proteger usuários e desenvolvedores de ataques.

Tabela 4. Estudos de modelos/métodos/técnicas de transparência em ECOS

\begin{tabular}{|c|c|c|}
\hline Modelos/Métodos/Técnicas & Parte do ECOS & Estudos \\
\hline Interface Translúcida & Arquitetura de ECOS & (CATALDO \& HERBSLEB, 2010) \\
Aplicativo de Transparência & $\begin{array}{c}\text { Aplicativos } \\
\text { disponibilizados em } \\
\text { ECOS }\end{array}$ & (FAHL et al., 2014) \\
\hline Avaliação da Transparência & Portais de ECOS & (MEIRELES et al., 2017b) \\
\hline
\end{tabular}

Por fim, o trabalho de Meireles et al. (2017b) trata de um estudo exploratório que busca analisar a transparência em portais de ECOS de forma sistematizada, a partir de um questionário para avaliar transparência em sites. Esse questionário foi adaptado para avaliar transparência em portais de ECOS. Nesse estudo, foram investigados dois portais de ECOS, o Portal do SPB e o Portal da Apple Store, com aplicação do questionário de transparência em sites. Com base nos resultados do estudo exploratório, construiu-se um questionário voltado para portais de ECOS, explorando a qualidade da informação (informativo) nas características 'clareza', 'acurácia', 'completeza', 'corretude', 'consistência' e 'integridade', bem como a auditabilidade do portal, com foco nas características 'explicável', 'rastreabilidade', 'verificabilidade', 'validação' e 'controlabilidade'. A contribuição do questionário voltado para portais está em analisar a transparência como mecanismo que influencia a forma como os diferentes atores buscam informações nos portais de ECOS, considerando a sua dimensão social.

\subsubsection{Sub-Q2: Quais as principais características que contribuem para a transparência em ECOS?}

A Tabela 5 lista as principais características que contribuem para a transparência em ECOS, identificadas nos estudos. Foi encontrado apenas um estudo que as relacionasse, conforme discutido na Seção 4.4.1.

Tabela 5. Características que contribuem para transparência

Fonte: (MEIRELES et al., 2017b)

\begin{tabular}{|l|l|}
\hline \multicolumn{2}{|c|}{ Características } \\
\hline Informativo & Auditabilidade \\
\hline Clareza & Explicável \\
\hline Acurácia & Rastreabilidade \\
\hline Completeza & Verificabilidade \\
\hline Corretude & Validação \\
\hline Consistência & Controlabilidade \\
\hline Integridade & \multicolumn{1}{|l}{} \\
\cline { 1 - 2 } &
\end{tabular}




\subsubsection{Sub-Q3: O que se sabe atualmente sobre os benefícios, desafios e limitações sobre transparência em ECOS?}

A Tabela 6 lista os principais benefícios, desafios e limitações da transparência em ECOS explorados nos estudos. Esses estudos mostram como a transparência pode influenciar no ecossistema, mais precisamente na forma como os diferentes atores buscam informações nos portais de ECOS, considerando a sua dimensão social.

Tabela 6. Benefícios, desafios e limitações de transparência em ECOS

\begin{tabular}{|c|c|}
\hline Benefícios/Desafios/Limitações da Transparência & Estudos \\
\hline Melhorar a experiência dos usuários em portais de ECOS. & MEIRELES et al. (2017b) \\
\hline Ser um mecanismo chave para coordenação do ECOS. & $\begin{array}{c}\text { CATALDO \& HERBSLEB (2010) } \\
\text { LINÃKER \& WNUK (2016) }\end{array}$ \\
\hline $\begin{array}{c}\text { Ter uma documentação não ambígua, acessível e de } \\
\text { forma clara. }\end{array}$ & $\begin{array}{c}\text { MOLDER et al. (2011) } \\
\text { GOYAL et al. (2017) }\end{array}$ \\
\hline $\begin{array}{c}\text { Ter um compartilhamento de repositórios e reutilização de } \\
\text { conton }\end{array}$ & $\begin{array}{c}\text { JANSEN et al. (2012) } \\
\text { HERBSLEB et al. (2016) }\end{array}$ \\
\hline $\begin{array}{c}\text { Comunicação transparente, que facilita a construção de } \\
\text { comunidades e apoia a aprendizagem. }\end{array}$ & $\begin{array}{c}\text { KNAUSS et al. (2018) } \\
\text { KNAUSS et al. (2014) }\end{array}$ \\
\hline $\begin{array}{c}\text { Ser um importante requisito não funcional que contribui } \\
\text { para a segurança. }\end{array}$ & VEGENDLA et al. (2018) \\
\hline $\begin{array}{c}\text { Ajudar a ter uma política clara a fim de resolver conflitos e } \\
\text { negociar custos relativos à mudança. }\end{array}$ & BOGART et al. (2016) \\
\hline $\begin{array}{c}\text { Auxiliar a tornar mais transparente o download de } \\
\text { aplicativos através do framework AT. }\end{array}$ & FAHL et al. (2014) \\
\hline
\end{tabular}

\subsubsection{Sub-Q4: Quais as implicações dos estudos sobre transparência em ECOS?}

Neste estudo, foram identificados três trabalhos que tiveram implicações diretas sobre transparência em ECOS. O trabalho de Cataldo \& Herbsleb (2010) explorou o conceito de interface translúcida para melhoria da transparência na arquitetura do ECOS. Por sua vez, o trabalho Fahl et al. (2014) fez um estudo de casos reais de aplicativos, mostrando as suas vulnerabilidades e ataques ocorridos, além de apresentar o framework AT, que beneficia o desenvolvimento e o uso de aplicativos. Por último, o trabalho de Meireles et al. (2017b) fez um estudo exploratório para a criação de um instrumento para avaliação de transparência em portais de ECOS. Esses estudos são mais explorados na Seção 4.4.1.

\subsection{Sumarização}

Nesta seção, foram analisadas publicações referentes à transparência em ECOS a partir de um mapeamento sistemático da literatura. A partir de um conjunto inicial de 26 publicações, foram selecionadas 12 publicações após uma avaliação dos estudos. No mapeamento sistemático, encontramos pesquisas que tratam de métodos, modelos e técnicas para avaliar a transparência em ECOS, uma focando na arquitetura, outra nos aplicativos disponibilizados e uma terceira em portais de ECOS. Quanto às características que contribuem para a transparência, destacaram-se informativo e auditabilidade.

Os benefícios, desafios e limitações da transparência ressaltados nos trabalhos convergem para o fato de que a transparência pode ser um mecanismo chave de apoiar os 
diferentes atores na busca por informações do ECOS e pode levar a uma comunicação clara, facilitando a construção de comunidades e apoiando a aprendizagem, podendo contribuir na melhoria da experiência dos desenvolvedores em portais de ECOS. Além disso, as implicações desses estudos levaram à criação do conceito de interface translúcida para arquitetura do ECOS, a um framework que beneficia o desenvolvimento e uso de aplicativos desenvolvidos em ECOS e, por último, a um questionário de avaliação da transparência em portais de ECOS.

\section{ITRANSPE: Um Instrumento para Avaliação de Mecanismos de Transparência em Portais de ECOS}

Essa seção descreve como o artefato derivado para portais de ECOS, a partir do refinamento do questionário para avaliação da transparência em sites (CARVALHO et al., 2017) com base nos resultados do estudo exploratório (MEIRELES et al., 2017ab) e do mapeamento sistemático (MEIRELES, 2018), foi evoluído para um instrumento para avaliação de mecanismos de transparência em portais de ECOS.

$\mathrm{O}$ artefato teve suas questões verificadas por especialistas a fim de permitir a construção do instrumento proposto. Os requisitos para a construção do artefato proposto foram inicialmente identificados por meio do estudo exploratório nos portais do SPB e da Apple Store, mediante a aplicação dos questionários de transparência em sites. Foi observado que esses portais de ECOS não foram projetados com a intenção de atender ao requisito da transparência. Seguiu-se então para uma adaptação do questionário proposto por Carvalho et al. (2017), que foi resultado de uma atualização de original proposto por Cappelli (2009), bem como para a condução de um mapeamento sistemático sobre transparência em ECOS, o que resultou no Instrumento para Avaliação de Mecanismos de Transparência em Portais de ECOS (ITRANSPE).

O instrumento foi construído na forma de uma planilha eletrônica, separada por abas, sendo cada uma delas referente às características de acessibilidade, de usabilidade, de informativo, de entendimento e de auditabilidade. A composição do questionário é mostrada na Tabela 7. Cada questão foi elaborada para contribuir com a análise de cada característica, visando à melhoria da transparência em algum serviço que o portal se propõe a oferecer. Nesse sentido, o questionário foi adaptado para atingir o maior número possível de elementos de portais de ECOS, tentando ser o mais genérico possível a fim de ser aplicado a qualquer portal, independente de foco, cabendo o responsável pelo portal direcionar a transparência ao objetivo que ele se propõe a atingir.

A partir deste questionário, prosseguiu-se para a avaliação com dez especialistas em ECOS. O objetivo deste estudo foi avaliar se determinada questão do questionário era válida, parcialmente válida ou inválida para o contexto dos portais de ECOS. Além disso, esses especialistas poderiam expor seus comentários e observações.

\subsection{Avaliação dos Especialistas}

Foi realizado um estudo com dez especialistas, indicados por um pesquisador doutor especialista no tópico ECOS. Os dez especialistas participaram dessa avaliação e receberam por e-mail o Questionário de Avaliação de Transparência em Portais de ECOS. O questionário foi enviado individualmente no período de 26/12/2017 a 28/12/2017, com prazo de 40 dias corridos, para que os especialistas avaliassem as questões relativas a cada característica que contribuem para a transparência. As observações foram retornadas 
até 31/01/2018, quando foi recebida a última avaliação. O perfil desses especialistas é apresentado na Tabela 8 .

Tabela 7. Composição do Questionário do ITRANSPE

\begin{tabular}{|c|c|c|c|}
\hline Características & $\begin{array}{c}\text { Número de } \\
\text { Questões }\end{array}$ & Características & $\begin{array}{c}\text { Número de } \\
\text { Questões }\end{array}$ \\
\hline \multicolumn{2}{|c|}{ Acessibilidade } & \multicolumn{2}{|c|}{ Informativo } \\
\hline Portabilidade & 1 & Clareza & 3 \\
\hline Publicidade & 2 & Acurácia & 1 \\
\hline Disponibilidade & 3 & Comparabilidade & 2 \\
\hline \multicolumn{2}{|c|}{ Usabilidade } & Atualidade & 1 \\
\hline Desempenho & 3 & Completeza & 1 \\
\hline Operabilidade & 3 & Corretude & 1 \\
\hline Adaptabilidade & 1 & Consistência & 1 \\
\hline Uniformidade & 2 & Integridade & 1 \\
\hline Intuitividade & 4 & \multicolumn{2}{|c|}{ Entendimento } \\
\hline Simplicidade & 2 & Compositividade & 1 \\
\hline Amigabilidade & 1 & Concisão & 1 \\
\hline & & Divisibilidade & 1 \\
\hline & & Dependência & 1 \\
\hline & & Detalhamento & 1 \\
\hline & & \multicolumn{2}{|c|}{ Auditabilidade } \\
\hline & & Explicação & 1 \\
\hline & & Rastreabilidade & 1 \\
\hline & & Verificabilidade & 1 \\
\hline & & Validade & 1 \\
\hline & & Controlabilidade & 1 \\
\hline
\end{tabular}

Todas as questões tinham três opções a selecionar - a questão é válida, a questão é parcialmente válida, ou a questão é inválida -, e todas elas tinham um espaço para inserir comentários. Os especialistas sinalizavam a sua resposta sobre a questão e deixavam comentários ou observações quando pertinente. O perfil resumido dos especialistas é mostrado na Tabela 8. Cada especialista respondeu 43 questões divididas entre 6 de acessibilidade, 16 de usabilidade, 11 de informativo, 5 de entendimento e 5 de auditabilidade. Nessa avaliação, não foi verificado o peso de certa característica em relação à transparência. $\mathrm{O}$ foco foi analisar se determinada questão é válida, parcialmente válida ou inválida, bem como verificar os comentários dos especialistas. O resultado da avaliação foi aferido primeiramente a partir do resultado geral pelas características principais: acessibilidade, usabilidade, informativo, entendimento e audibilidade.

Conforme resultado mostrado na Tabela 9, percebe-se que auditabilidade obteve o maior resultado de questões válidas seguido de informativo, acessibilidade, usabilidade e entendimento. O principal ponto nesse primeiro momento foi verificar que $68,43 \%$ das 430 respostas resultantes das 43 questões analisadas pelos dez especialistas foram consideradas válidas e apenas $8,06 \%$ das questões foram consideradas inválidas para um portal de ECOS. Por último, foi aplicado o filtro por questão, cujo resultado é apresentado na Tabela 10. Com base no resultado, foram feitas algumas alterações nas questões. A principal delas foi a utilização do conceito de serviço de Cartlidge et al. (2008), definido como uma forma de entregar valor ao cliente, facilitando o resultado almejado por eles sem a necessidade de arcar com custos específicos e riscos. Neste caso, não seria processo 
ou atividade como estava no questionário, pois o conceito de serviço está mais coerente com o objetivo dos ECOS.

Tabela 8. Perfil resumido dos especialistas

\begin{tabular}{|c|c|c|}
\hline & Grau Acadêmico & Atuação Profissional \\
\hline E1 & Cursando Doutorado em Informática & ECOS e Engenharia de Software \\
\hline E2 & Mestre em Informática & ECOS e Análise de Sistema \\
\hline E3 & Cursando Doutorado em Informática & Análise de Sistema e ECOS \\
\hline E4 & Doutor em Informática & $\begin{array}{l}\text { Modelos de Maturidade e Engenharia de } \\
\text { Software }\end{array}$ \\
\hline E5 & Doutor em Informática & $\begin{array}{l}\text { Engenharia de Software e Gestão de Processo } \\
\text { de Negócio }\end{array}$ \\
\hline E6 & Mestre em Informática & Arquiteto de Software e Sistemas de Informação \\
\hline E7 & Doutor em Informática & $\begin{array}{l}\text { Engenharia de Software e Melhoria nos } \\
\text { Processos }\end{array}$ \\
\hline E8 & Cursando Doutorado em Informática & Experimentação e Teste de Software \\
\hline E9 & Mestrado em Informática & $\begin{array}{l}\text { Governança em Tecnologia de Informação e } \\
\text { Engenharia de Requisitos }\end{array}$ \\
\hline $\begin{array}{l}\text { E1 } \\
0\end{array}$ & Mestre em Informática & ECOS e Análise de Sistema \\
\hline
\end{tabular}

A fim de enriquecer o trabalho, foi acrescentado alguns comentários dos especialistas. Com o objetivo de diferenciá-los, cada especialista $E$ recebeu um identificador, conforme a Tabela 8. Sobre a Questão 1 da característica acessibilidade, E1 a considerou válida e colocou como comentário "acesso multiplataforma facilita o acesso de diversos perfis de usuário". E2 também considerou esta questão válida e comentou que "garantir que o portal com informações de ECOS abre e funciona com bom desempenho e boa experiência para o usuário é essencial. Ao mesmo tempo fico me perguntando o quanto essa questão é importante para qualquer portal/site da internet e o quanto é relevante para sua pesquisa". E3 considerou a questão parcialmente inválida e emitiu o seguinte comentário: "A questão é sempre válida, ocorre que deveria ser melhor contextualizado, em terras de survey, o que deveria ser melhor contextualizado, em terras de survey, o que se entende como portais de ECOS. Essa questão, por exemplo vale para qualquer topo de portal e não apenas para ECOS". Como último exemplo, apresentamos um comentário feito por E4 sobre a Questão 1 da característica usabilidade: "A questão de navegabilidade cobre isso não? Refere a layout...".

Outras alterações que ocorreram foram pontuais como, por exemplo, na Questão 2 da característica simplicidade, cuja pergunta foi ajustada para: Usando poucos cliques, é possivel executar o serviço esperado? Por sua vez, a Questão 1 da característica 
divisibilidade também foi alterada, a partir da contribuição dos especialistas, ficando dessa forma: O Portal divide os códigos por linguagens de programação?

Tabela 9. Resultado da pesquisa com especialistas (por característica)

\begin{tabular}{|c|c|c|c|c|c|}
\hline Resultado da pesquisa & Questões & Respostas & $\%$ válida & $\begin{array}{c}\% \\
\text { parcial }\end{array}$ & $\begin{array}{c}\% \\
\text { inválida }\end{array}$ \\
\hline Acessibilidade & 6 & 60 & $65,00 \%$ & $30,00 \%$ & $5,00 \%$ \\
\hline Usabilidade & 16 & 160 & $61,88 \%$ & $25,00 \%$ & $13,12 \%$ \\
\hline Informativo & 11 & 110 & $77,27 \%$ & $14,55 \%$ & $8,18 \%$ \\
\hline Entendimento & 5 & 50 & $52,00 \%$ & $40,00 \%$ & $8,00 \%$ \\
\hline Auditabilidade & 5 & 50 & $86,00 \%$ & $8,00 \%$ & $6,00 \%$ \\
\hline \multicolumn{7}{|c|}{ Total: } & & $\mathbf{6 8 , 4 3 \%}$ & $\mathbf{2 3 , 5 1 \%}$ & $\mathbf{8 , 0 6 \%}$ \\
\hline
\end{tabular}

Por fim, duas questões foram retiradas da característica usabilidade. Uma dessas questões se referia à característica desempenho. Com base nas opiniões dos especialistas, a Questão 2 estava sendo atendida pela Questão 1 e optou-se por eliminar essa questão ("o tempo de download dos códigos ou programas dos portais é adequado?"). A outra foi a Questão 1 da característica uniformidade: "o portal fica trocando os principais frames e elementos de posição?", que foi excluída por ter sido considerada inválida por $30 \%$ das avaliações e pelos comentários deixados.

\subsection{Primeira Versão do ITRANSPE}

$\mathrm{O}$ artefato gerado a partir da avaliação com especialistas corresponde à primeira versão do ITRANSPE. Nesta versão, o ITRANPE consiste de uma planilha eletrônica, dividida em abas, onde cada aba corresponde a uma característica que contribui com a transparência, isto é, acessibilidade, usabilidade, informativo, entendimento e auditabilidade. As questões e as sugestões de acessibilidade focam nas características portabilidade, publicidade e desempenho, contribuindo para que o portal de ECOS torne os serviços mais acessíveis aos desenvolvedores. Com isso, pode-se contribuir com a melhoria dessa característica.

As questões e as sugestões de usabilidade evidenciam as características desempenho, operabilidade, adaptabilidade, uniformidade, intuitividade, simplicidade e amigabilidade. Dessa forma, buscam sinalizar aos desenvolvedores a efetividade, eficiência e satisfação no portal de ECOS. As questões e as sugestões de informativo enfatizam as características clareza, acurácia, comparabilidade, atualidade, completeza, corretude, consistência e integridade. Assim, procuram sinalizar aos desenvolvedores a qualidade nas informações e nos serviços oferecidos. Por sua vez, as questões e as sugestões de entendimento evidenciam as características compositividade, concisão, divisibilidade, dependência e detalhamento, visando enfatizar aos desenvolvedores a compreensão do portal de ECOS que eles utilizam. Por fim, as questões de auditabilidade, que enfatizam as características explicação, rastreabilidade, verificabilidade, validade e controlabilidade, procuram sinalizar aos desenvolvedores que o portal de ECOS está funcionando de acordo com o que promete. 
Tabela 10. Resultado da pesquisa com especialistas

\begin{tabular}{|c|c|c|c|c|c|c|c|}
\hline Acessibilidade & Válida & Parcial & Inválida & Informativo & Válida & Parcial & Inválida \\
\hline$\underline{\text { Portabilidade }}$ & & & & $\underline{\text { Clareza }}$ & & & \\
\hline Questão 1 & 5 & 5 & & Questão 1 & 10 & & \\
\hline Publicidade & & & & Questão 2 & 9 & 1 & \\
\hline Questão 1 & 5 & 4 & 1 & Questão 3 & 8 & 2 & \\
\hline Questão 2 & 5 & 5 & & Acurácia & & & \\
\hline Disponibilidade & & & & Questão 1 & 8 & 1 & 1 \\
\hline Questão 1 & 8 & 2 & & Comparabilidade & & & \\
\hline Questão 2 & 8 & 1 & 1 & Questão 1 & 6 & 3 & \\
\hline Questão 3 & 8 & 1 & 1 & Questão 2 & 7 & 2 & 1 \\
\hline & & & & Atualidade & & & \\
\hline Usabilidade & Válida & Parcial & Inválida & Questão 1 & 9 & 1 & 0 \\
\hline Desempenho & & & & Completeza & & & \\
\hline Questão 1 & 6 & 3 & 1 & Questão 1 & 6 & 2 & 2 \\
\hline Questão 2 & 4 & 5 & 1 & Corretude & & & \\
\hline Questão 3 & 6 & 3 & 1 & Questão 1 & 7 & 1 & 2 \\
\hline Operabilidade & & & & Consistência & & & \\
\hline Questão 1 & 8 & 1 & 1 & Questão 1 & 7 & 2 & 0 \\
\hline Questão 2 & 7 & 2 & 1 & Integridade & & & \\
\hline Questão 3 & 7 & 2 & & Questão 1 & 8 & 1 & 0 \\
\hline Adaptabilidade & & & & Entendimento & Válida & Parcial & Inválida \\
\hline Questão 1 & 7 & 2 & 1 & Compositividade & & & \\
\hline$\underline{\text { Uniformidade }}$ & & & & Questão 1 & 6 & 3 & 1 \\
\hline Questão 1 & 5 & 2 & 3 & Concisão & & & \\
\hline Questão 2 & 5 & 3 & 2 & Questão 1 & 5 & 4 & 1 \\
\hline$\underline{\text { Intuitividade }}$ & & & & Divisibilidade & & & \\
\hline Questão 1 & 6 & 4 & & Questão 1 & 3 & 5 & 2 \\
\hline Questão 2 & 7 & 2 & 1 & Dependência & & & \\
\hline Questão 3 & 7 & 1 & 2 & Questão 1 & 7 & 3 & 0 \\
\hline Questão 4 & 6 & 2 & 2 & Detalhamento & & & \\
\hline$\underline{\text { Simplicidade }}$ & & & & Questão 1 & 5 & 5 & 0 \\
\hline Questão 1 & 7 & 1 & 2 & Auditabilidade & Válida & Parcial & Inválida \\
\hline Questão 2 & 4 & 3 & 3 & Explicação & & & \\
\hline Amigabilidade & & & & Questão 1 & 9 & 1 & 0 \\
\hline Questão 1 & 7 & 3 & 0 & $\underline{\text { Rastreabilidade }}$ & & & \\
\hline & & & & Questão 1 & 10 & 0 & 0 \\
\hline & & & & $\underline{\text { Verificabilidade }}$ & & & \\
\hline & & & & Questão 1 & 7 & 2 & 1 \\
\hline & & & & Validade & & & \\
\hline & & & & Questão 1 & 8 & 0 & 1 \\
\hline & & & & Controlabilidade & & & \\
\hline & & & & Questão 1 & 9 & 1 & 0 \\
\hline
\end{tabular}




\section{Avaliação}

Essa seção trata da avaliação do ITRANSPE com relação à opinião dos desenvolvedores de software que utilizam portais de ECOS. Esta avaliação foi realizada visando analisar aspectos de facilidade de uso e de utilidade do instrumento, buscando obter contribuições para a melhoria do ITRANSPE. Nesse sentido, o Portal do SPB foi selecionado, dado que é um dos cinco ECOS mais explorados na literatura segundo uma revisão de literatura de referência no assunto (MANIKAS \& HANSEN, 2013).

Além disso, o Portal de Desenvolvimento dos Correios foi selecionado por conveniência (vínculo empregatício de um dos pesquisadores que desenvolveram este trabalho). Apesar de ser uma organização consumidora de software, os Correios têm desenvolvedores internos e empresas de desenvolvimento (fornecedores) para construção de sistemas de software que atendam a alguma necessidade de negócio, formando a base de ativos de software (plataforma do ECOS). Para isso, eles utilizam ferramentas para apoiar os atores a obterem informações do ecossistema, disponibilizadas apenas para os Correios e empresas que estejam trabalhando no desenvolvimento de algum software para essa organização. O Portal de Desenvolvimento dos Correios foi adquirido pelos Correios e se chama Taiga, cuja plataforma tecnológica consiste em uma ferramenta que utiliza métodos ágeis de desenvolvimento e que pode ser customizada. Os Correios utilizam esse portal como ferramenta para apoiar os diferentes atores a acessarem informações dos projetos de desenvolvimento de software.

\subsection{Planejamento}

O ITRANSPE foi avaliado por meio de um estudo de viabilidade, cujo planejamento está descrito nesta seção. Neste estudo, foi utilizado o Modelo de Aceitação de Tecnologia (TAM) (DAVIS, 1993). A avaliação no modelo TAM é fundamentada em dois conceitos: (i) percepção sobre facilidade de uso e (ii) percepção sobre utilidade. Nesse sentido, o objetivo foi avaliar a viabilidade do ITRANSPE no ponto de vista de desenvolvedores que utilizam portais de ECOS para apoiar a construção de software e aplicativos. Entre os objetivos, estão: (1) caracterizar benefícios e deficiências do apoio do ITRANSPE à avaliação da transparência em portais de ECOS; (2) caracterizar facilidade de uso do ITRANSPE; e (3) caracterizar utilidade do ITRANSPE.

Os objetivos são especificados no formato GQM (Goal-Question-Metric) (BASILI et al., 1994), sumarizados na Figura 2 e descritos pelas Tabelas 11, 12 e 13. A questão de pesquisa principal para este estudo é definida em Q1 e visa verificar se os participantes são capazes de perceber as características da transparência em portais de ECOS: Q1) Os participantes são capazes de perceber as características da transparência em portais de ECOS? (SIM, NÃO ou PARCIALMENTE). Esta percepção é coletada a partir das respostas dos participantes nas questões de feedback.

Conforme ilustrado na Figura 2, existem outras oito questões (Q2 a Q9) associadas aos objetivos G2 e G3 do modelo GQM. Estas questões têm o objetivo de capturar as percepções de facilidade de uso e de utilidade do ITRANSPE, conforme a Tabela 14, cujas respostas consistem em um valor na escala Likert de cinco pontos: discordo totalmente, discordo, não concordo nem discordo, concordo, concordo totalmente. Adicionalmente, os participantes do estudo foram selecionados por conveniência a partir 
de dois grupos: (1) Desenvolvedores do Portal do Software Público Brasileiro (SPB); e (2) Desenvolvedores que utilizam o Portal de Desenvolvimento dos Correios.

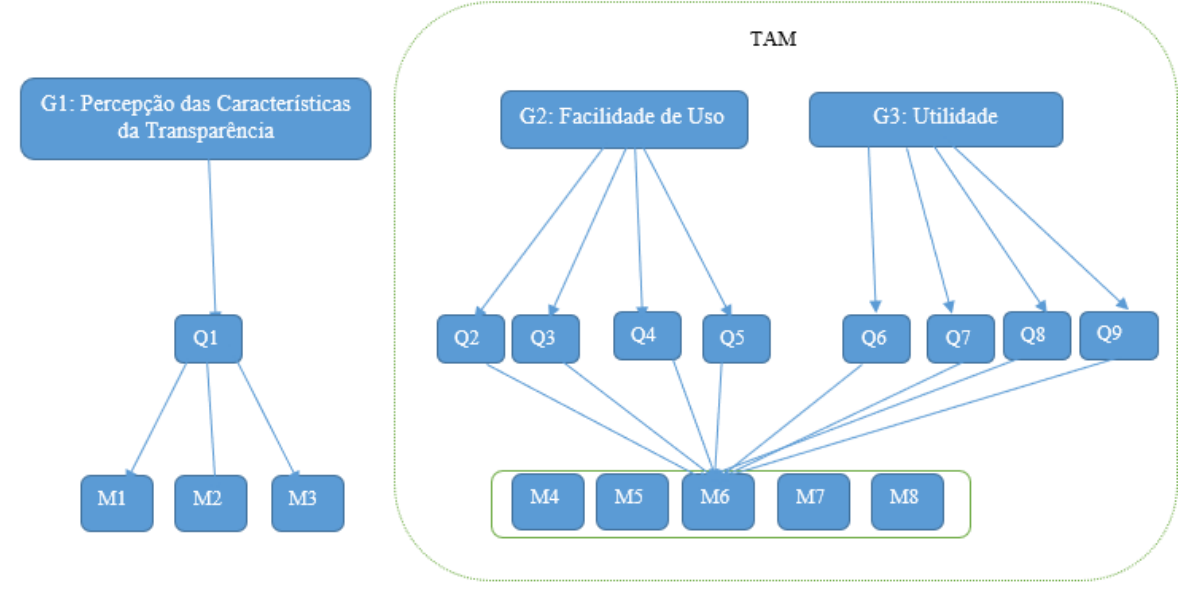

Figura 2. Modelo GQM para o estudo de viabilidade

Tabela 11. Objetivo G1 (Viabilidade)

\begin{tabular}{|l|l|}
\hline Analisar & ITRANSPE \\
\hline Com o propósito de & Caracterizar \\
\hline Com respeito a & Percepção das características da transparência \\
\hline Do ponto de vista de & Desenvolvedores \\
\hline No contexto de & Portais de ECOS \\
\hline
\end{tabular}

Tabela 12. Objetivo G2 (Facilidade de Uso)

\begin{tabular}{|l|l|}
\hline Analisar & ITRANSPE \\
\hline Com o propósito de & Caracterizar \\
\hline Com respeito a & Facilidade de uso \\
\hline Do ponto de vista de & Desenvolvedores \\
\hline No contexto de & Portais de ECOS \\
\hline
\end{tabular}

Tabela 13. Objetivo G3 (Utilidade)

\begin{tabular}{|l|l|}
\hline Analisar & ITRANSPE \\
\hline Com o propósito de & Caracterizar \\
\hline Com respeito a & Utilidade \\
\hline Do ponto de vista de & Desenvolvedores \\
\hline No contexto de & Portais de ECOS \\
\hline
\end{tabular}

Neste estudo, foram definidas tarefas que os desenvolvedores deveriam seguir: (1) aplicar cada questão do ITRANSPE no respectivo portal de ECOS, considerando experiência em tarefas que fazem parte do seu dia a dia; (2) em seguida, analisar as sugestões de melhoria da transparência; e, por fim, (3) verificar se tais sugestões podem contribuir com a melhoria da sua experiência com o portal de ECOS. O estudo se concentrou em observar a influência da transparência em portais de ECOS - neste caso, o Portal do SPB e no Portal de Desenvolvimento dos Correios.

\subsection{Instrumentação e Preparação}

Nesta parte, define-se quais recursos serão utilizados durante a avaliação e como a avaliação será preparada. Para este estudo, foram projetados seis instrumentos principais: (1) Termo de Consentimento Livre e Esclarecido; (2) Formulário de Caracterização do 
Participante; (3) Embasamento Teórico sobre ECOS; (4) Guia do Uso do Instrumento; (5) Formulário para Realização do Estudo; e (6) Formulário de Avaliação do Estudo.

Tabela 14. Questões do modelo TAM para avaliação do ITRANSPE

\begin{tabular}{|c|c|c|}
\hline Questão & Descrição & Aspecto \\
\hline Q2 & Foi fácil aprender a utilizar o ITRANSPE. & \multirow{4}{*}{$\begin{array}{l}\text { Facilidade } \\
\text { de Uso }\end{array}$} \\
\hline Q3 & Consegui utilizar o ITRANSPE da forma que eu queria. & \\
\hline Q4 & Entendi o que acontecia na minha interação com o ITRANSPE. & \\
\hline Q5 & Foi fácil responder as questões do ITRANSPE. & \\
\hline Q6 & $\begin{array}{l}\text { Considero o ITRANSPE útil para avaliar características de } \\
\text { transparência no portal do ECOS. }\end{array}$ & \multirow{4}{*}{ Utilidade } \\
\hline Q7 & $\begin{array}{l}\text { O ITRANSPE permite que eu entenda como as características } \\
\text { que contribuem para a transparência se relacionam com os } \\
\text { elementos do portal do ECOS. }\end{array}$ & \\
\hline Q8 & $\begin{array}{l}\text { O ITRANSPE me ajudou a identificar oportunidades de } \\
\text { melhorias no portal do ECOS. }\end{array}$ & \\
\hline Q9 & $\begin{array}{l}\text { O ITRANSPE propõe soluções que melhoram a transparência } \\
\text { de acordo com o objetivo do portal do ECOS. }\end{array}$ & \\
\hline
\end{tabular}

O termo de consentimento assegura a concordância do participante sobre utilizar os dados providos de forma anônima e confidencial. Após o consentimento, o participante responde ao formulário de caracterização utilizado para apoiar a análise dos dados. $\mathrm{O}$ conceito de ECOS é introduzido no documento de embasamento teórico e as instruções para o preenchimento do questionário são disponibilizadas para consulta a qualquer momento para os participantes. O formulário para realização do estudo contém a contextualização e as instruções básicas para responder o ITRANSPE. O participante aplica, então, o ITRANSPE no Portal do SPB ou no Portal de Desenvolvimento dos Correios. Por último, cada participante responde o formulário de avaliação do estudo para obter impressões, sugestões e outras informações da sua percepção.

Os resultados deste estudo foram analisados de forma quantitativa e qualitativa, com base: (i) nas respostas fornecidas pelos participantes no formulário para avaliação do estudo; e (ii) nas considerações feitas pelos participantes sobre facilidade de uso e utilidade no formulário para avaliação do estudo.

\subsection{Estudo Piloto}

Um estudo piloto foi conduzido em julho de 2018 com dois participantes na mesma sala, ao mesmo tempo, supervisionados por um pesquisador. $\mathrm{O}$ primeiro participante possui um pós-doutorado e o segundo possui mestrado incompleto. $\mathrm{O}$ primeiro participante informou nível médio de experiência em desenvolvimento colaborativo e redes sociais e nível alto de engenharia de software; por sua vez, o segundo tem nível médio de redes sociais e nível alto de engenharia de software e desenvolvimento colaborativo. Depois de registrar o e-mail no termo de consentimento e responder às questões de caracterização, eles receberam o embasamento teórico, o guia do uso do instrumento, o formulário para realização do estudo e o ITRANSPE. Ambos executaram as tarefas sem nenhum auxílio.

O primeiro participante não conseguiu efetivamente responder todas as questões propostas; ficou satisfeito com as sugestões de melhorias; concordou que a transparência 
pode trazer ganhos para o seu trabalho; considerou difícil responder as questões do ITRANSPE; e considerou que a maior dificuldade encontrada em utilizar o ITRANSPE foi a falta de conhecimento no portal de ECOS. Por sua vez, o segundo participante conseguiu responder efetivamente às questões propostas; também ficou satisfeito com as sugestões de melhoria da transparência; concordou que o aumento da transparência pode trazer ganhos para o seu trabalho; considerou fácil responder às questões do ITRANSPE; e considerou que a maior dificuldade foi o uso do ITRANSPE sem uma ajuda.

O primeiro participante considerou que as questões da aba informativo têm maior relação com seu trabalho no portal. Além disso, listou como aspecto positivo a identificação de oportunidades de melhorias e, como negativo, que o público deve ter bom conhecimento do portal. Como sugestão de melhoria, solicitou a opção de resposta 'não possui a funcionalidade'. O segundo participante considerou que o registro de interações entre os usuários tem maior relação com seu trabalho. Listou como aspecto positivo a melhoria da ferramenta disponibilizada na empresa, não considerou aspectos negativos e indicou, como sugestão de melhoria, apoiar a direcionar para um perfil específico de usuário.

Dessa forma, o estudo piloto identificou oportunidades de melhorias nos formulários do estudo. A principal delas foi explicar mais detalhadamente o que é um ECOS. Com isso, seguiu-se para a versão final dos formulários, que foram aplicados com desenvolvedores dos ECOS SPB e Correios.

\subsection{Execução}

Os e-mails dos participantes do ECOS SPB foram coletados a partir de dois repositórios públicos, acessados no dia 28 de julho de 2018 (https://softwarepublico.gov.br/gitlab/ softwarepublico/softwarepublico/graphs/master e https://softwarepublico.gov.br/gitlab/ softwarepublico/colab/graphs/master). Consolidou-se uma planilha e verificou-se os emails válidos, eliminando-se os repetidos, a fim de prosseguir com o estudo. Foram enviados os e-mails de convite no dia 9 de julho de 2018. Registrou-se na mesma tabela os e-mails retornados. Solicitou-se retorno ao estudo até o dia 31 de julho de 2018.

Para a execução do estudo no ECOS Correios, aproveitou-se o conhecimento do pesquisador para indicar pessoas que trabalham no desenvolvimento de software e utilizam o Taiga como portal para acessar informações do ecossistema. O envio dos convites aos possíveis participantes ocorreu no dia 10 de julho e o prazo para retorno também foi até o dia 31 de julho de 2018.

Devido à dificuldade de receber respostas nos dois ECOS, foram enviados novamente e-mails de convite no dia 23 de julho de 2018 e no dia 02 de agosto de 2018 , com prazo de retorno prorrogado até 07 de agosto de 2018 e depois até 10 de agosto de 2018 (prazo final). No dia 04 de agosto de 2018, tinham sido recebidas seis respostas, cinco referentes ao ECOS SPB e uma referente ao ECOS Correios. Devido à baixa quantidade de respostas dos Correios, no dia 06 de agosto de 2018, fez-se contatos telefônicos com funcionários que receberam o convite a fim de verificar participação do estudo. Esta ação resultou em mais duas respostas. No total, foram considerados oito participantes, cinco do Portal do SPB e três do Portal de Desenvolvimento dos Correios. 


\subsection{Ameaças à Validade}

As características de um estudo comumente podem influenciar a validade dos resultados, o que é conhecido como ameaças à validade. Há quatro tipos de validade dos resultados do estudo: validade interna, validade externa, validade de construto e validade de conclusão (WOHLIN et al., 1999; TRAVASSOS et al., 2002). Para este estudo, foram identificadas as ameaças à validade a seguir:

Validade interna: define se a relação entre o tratamento e o resultado é casual e derivado de influências de outros fatores descontrolados ou mesmo não medidos:

- A seleção dos participantes do estudo pode influenciar os resultados. Buscouse contemplar dois ECOS reais;

- O próprio questionário pode influenciar os resultados, caso os participantes enfrentem dificuldades de entendimento. Procurou-se orientar em observar as dicas e os exemplos;

- O intercâmbio de informações com outros participantes que conduziram o estudo. Para reduzir este risco, o e-mail com a pesquisa foi enviado individualmente;

- O entendimento dos participantes sobre as questões dos formulários é diretamente influenciado pela forma como as questões foram elaboradas; se a questão tiver sido mal formulada, o estudo pode ser afetado negativamente. Buscou-se fazer um piloto antes da execução do estudo propriamente dito; e

- Para a análise dos dados, foram utilizadas as informações de caracterização fornecidas pelos próprios participantes sem qualquer certificação de que estejam corretas.

Validade externa: define as condições que podem dificultar a generalização dos resultados para outros contextos:

- Não é possível representar todas as situações possíveis de um portal de ECOS. Estudos em diferentes portais devem ser realizados. Infelizmente, comunidades de pesquisa geralmente enfrentam desafios para estabelecer parcerias para coletar dados reais e avaliar soluções propostas.

Validade de construto: considera as relações entre a teoria e a observação, ou seja, se o tratamento da pesquisa reflete a causa e o resultado reflete o efeito:

- As medidas selecionadas para captura dos resultados podem não ser as mais adequadas para avaliar a validade do questionário. Para minimizar esse risco, foram selecionadas medidas que visam capturar as informações necessárias para responder às questões do estudo; e

- Os participantes foram escolhidos por conveniência de disponibilidade, não levando em conta e experiência no ECOS. Esta é uma ameaça à validade, pois seu comportamento pode ser alterado para influenciar o resultado.

Validade de conclusão: refere-se às condições para tirar conclusões corretas sobre as relações entre a pesquisa e os resultados:

- O tamanho da amostra pode limitar a validade do estudo. Por isso, este estudo apresenta uma limitação de análises mais robustas dos resultados e considera a interpretação dos resultados somente como indícios (e não evidências). 


\subsection{Resultados}

Com o objetivo de caracterizar melhor os participantes, os resultados foram separados por grupo de participantes: o primeiro grupo agrupa os participantes que analisaram o Portal do SPB (G1P*) e o segundo grupo agrupa os participantes que analisaram o Portal de Desenvolvimento dos Correios (G2P*), onde '*' é a diferenciação de cada participante. $\mathrm{Na}$ caracterização dos participantes, identificou-se a formação acadêmica, o grau de experiência, o tempo de experiência e a experiência com ferramentas similares. $\mathrm{O}$ grau de experiência foi informado pelos participantes de acordo com as seguintes escalas:

- $0=$ nenhum (nunca participou de atividades deste tipo);

- 1 = estudou em aula ou em livro (possui o conhecimento teórico apenas);

- 2 = praticou projetos em sala de aula (possui conhecimento teórico aplicado apenas no contexto acadêmico);

- 3 = usou em projetos pessoais (possui conhecimento teórico somado de experiência e práticas individuais);

- $4=$ usou em poucos projetos na indústria (possui conhecimento teórico somado de experiência práticas reais); e

- $5=$ usou em muitos projetos na indústria (possui conhecimento teórico somado de muitas experiências práticas reais).

Por sua vez, a escala de experiência com ferramentas similares foi:

- 0 = Não tem familiaridade com este tipo de ferramenta;

- 1 = Tem alguma familiaridade com este tipo de ferramenta; e

- 2 = Tem muita familiaridade com este tipo de ferramenta.

A Figura 3 apresenta a caracterização dos participantes do Portal do SPB e a Figura 4 mostra a do Portal de Desenvolvimento dos Correios. Um participante não respondeu o tempo de experiência, mas se optou por mantê-lo no estudo devido o foco em analisar a facilidade de uso e a utilidade do instrumento.

Em G1 (Portal do SPB), o resultado da percepção dos desenvolvedores foi:

- cinco conseguiram efetivamente responder a todas as questões propostas, dois ficaram satisfeitos, dois parcialmente e um não ficou satisfeito;

- dois ficaram satisfeitos com as sugestões de melhoria da transparência, dois parcialmente e um não ficou satisfeito;

- no ponto de vista de três deles, o aumento da transparência pode trazer ganho para o seu trabalho, usando as sugestões apresentadas, e parcialmente no ponto de vista de dois; e

- quatro consideraram fácil e apenas um considerou difícil responder as questões do ITRANSPE.

Os participantes G1P2 e G1P5 não fizeram nenhum comentário ou emitiram opinião sobre o ITRANSPE. Por sua vez, G1P3 não teve dificuldade em utilizar o instrumento e considerou a auditabilidade a característica que tem maior relação com o seu trabalho no portal. O participante listou como aspectos positivos a objetividade e a concisão do instrumento, considerou que não teve aspectos negativos e comentou, como sugestão de melhoria, a elaboração de uma planilha resumo, apresentando as sugestões separadas por características avaliadas exploradas no ITRANSPE e que têm maior relação com o seu trabalho no portal de ECOS. Nesse contexto, dois participantes apontaram auditabilidade, um indicou informativo, outro citou uma recomendação da característica 
informativo e, por último, um participante colocou confiabilidade, que, apesar de não estar nas características, tem relação com auditabilidade e informativo.

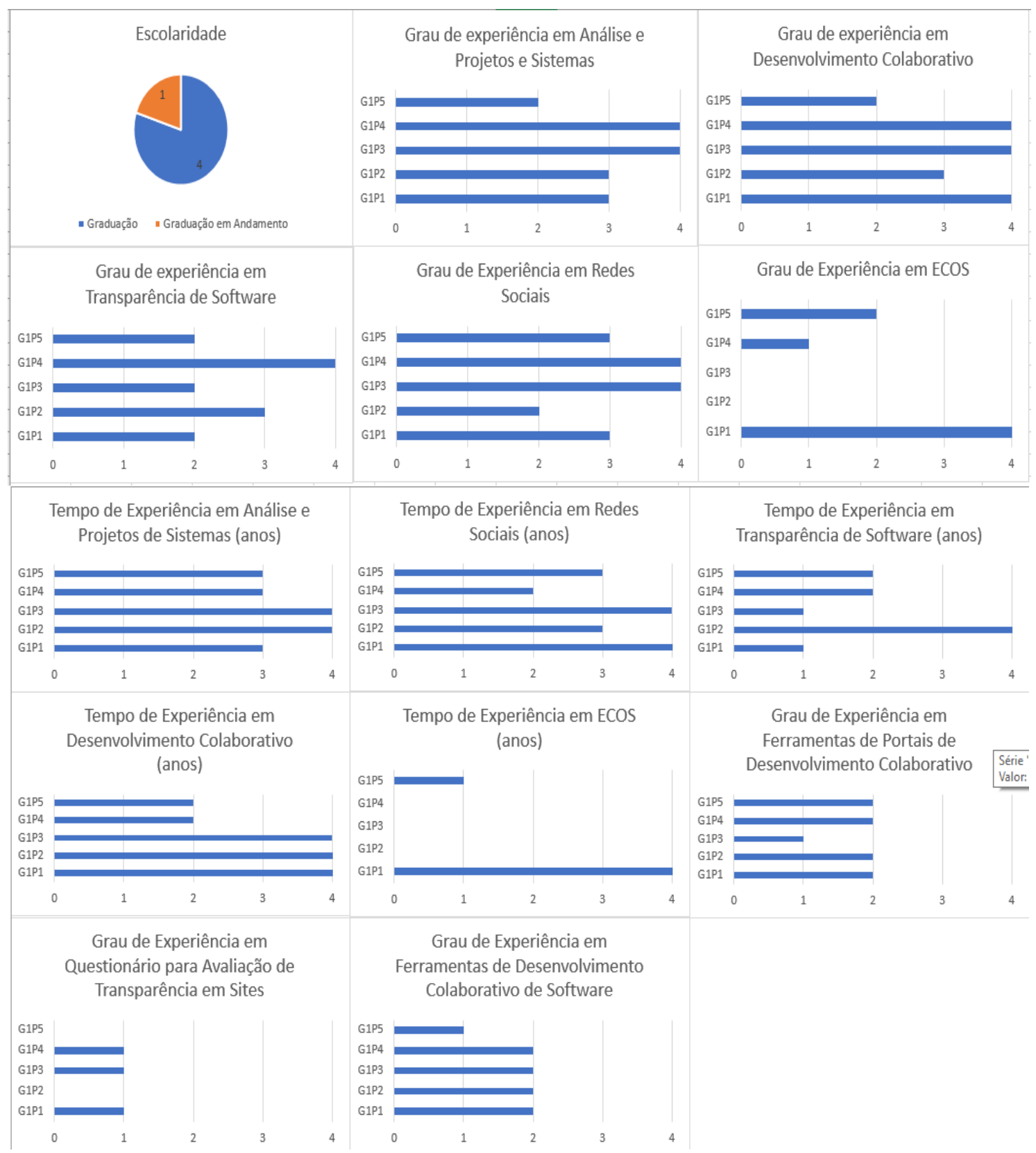

Figura 3. Caracterização dos participantes do estudo no Portal do SPB

Foram feitas oito afirmações para esse grupo sobre percepções de facilidade de uso (Figura 5) e de utilidade (Figura 6), para que os participantes do estudo pudessem responder se discordavam totalmente, discordavam, não concordavam e nem discordavam, concordavam ou concordavam totalmente. G1P4 considerou que a maior dificuldade encontrada foi a quantidade de perguntas, mas comentou que os exemplos auxiliaram muito na compreensão das características que tem maior relação com o seu trabalho no dia a dia. 


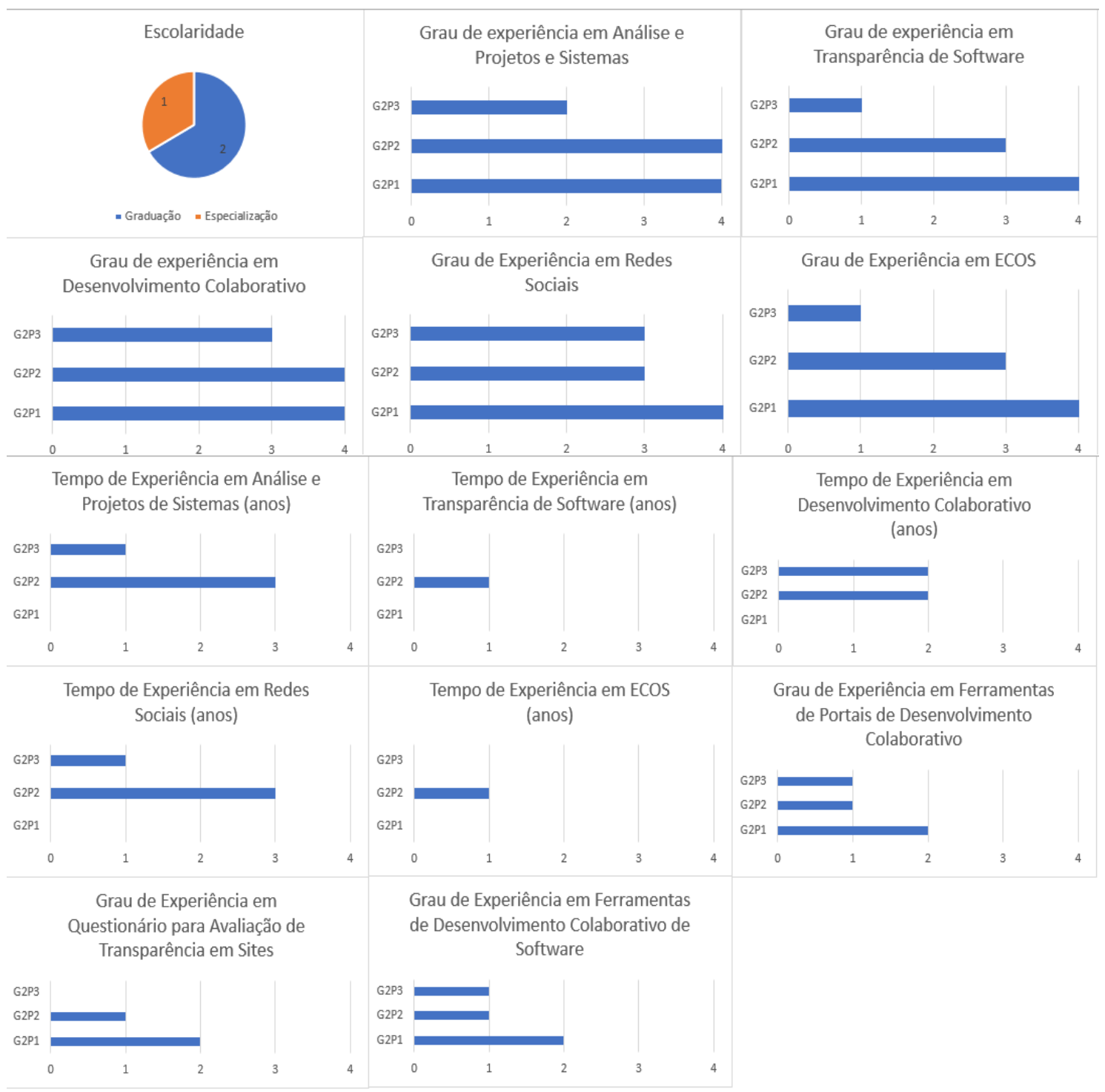

Figura 4. Caracterização dos participantes do estudo no Portal dos Correios

O participante fez ainda um comentário, que é transcrito a seguir: 'Eu trabalhei na criação do portal (SPB), uma melhoria interessante é a busca por download e consequentemente a relevância do software'. Por último, G1P4 listou como aspecto positivo do ITRANSPE: trazer maior clareza de boas práticas em softwares públicos que estão disponíveis para os usuários.

Em G2 (Portal de Desenvolvimento dos Correios), o resultado da percepção dos desenvolvedores foi:

- os três participantes conseguiram efetivamente responder todas as questões propostas no ITRANSPE;

- ficaram satisfeitos com as sugestões de melhoria da transparência;

- no seu ponto de vista, concordaram que o aumento da transparência pode trazer ganhos para o trabalho de desenvolvedor usando as sugestões dadas; e

- dois concordaram que foi fácil responder as questões do ITRANSPE e um considerou muito fácil. 
Também foram feitas as mesmas oito afirmações para esse grupo. Os resultados estão dispostos na Figura 7 (percepções de facilidade de uso) e na Figura 8 (percepções de utilidade). G2P1 reportou, como características exploradas no ITRANSPE e que têm maior relação com seu trabalho, 'confiabilidade', mesmo esta característica não estando explícita no ITRANSPE. Como aspectos positivos, listou interatividade e fácil assimilação (não observou pontos negativos). Por sua vez, G2P2 e G2P3 informaram auditabilidade e informativo, respectivamente, e não observaram pontos negativos.

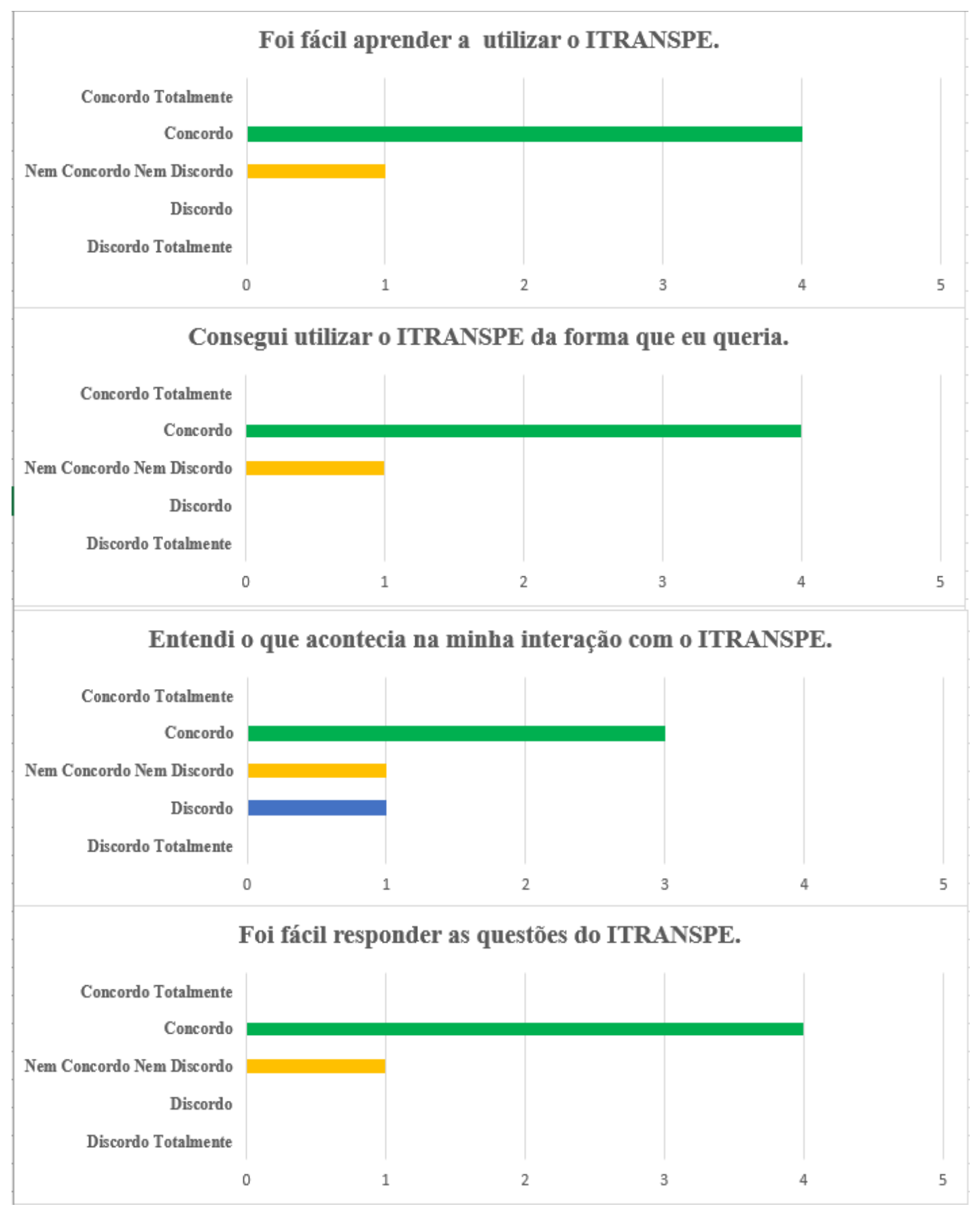

Figura 5. Resultados sobre Percepções de Facilidade de Uso do ITRANSPE (SPB) 


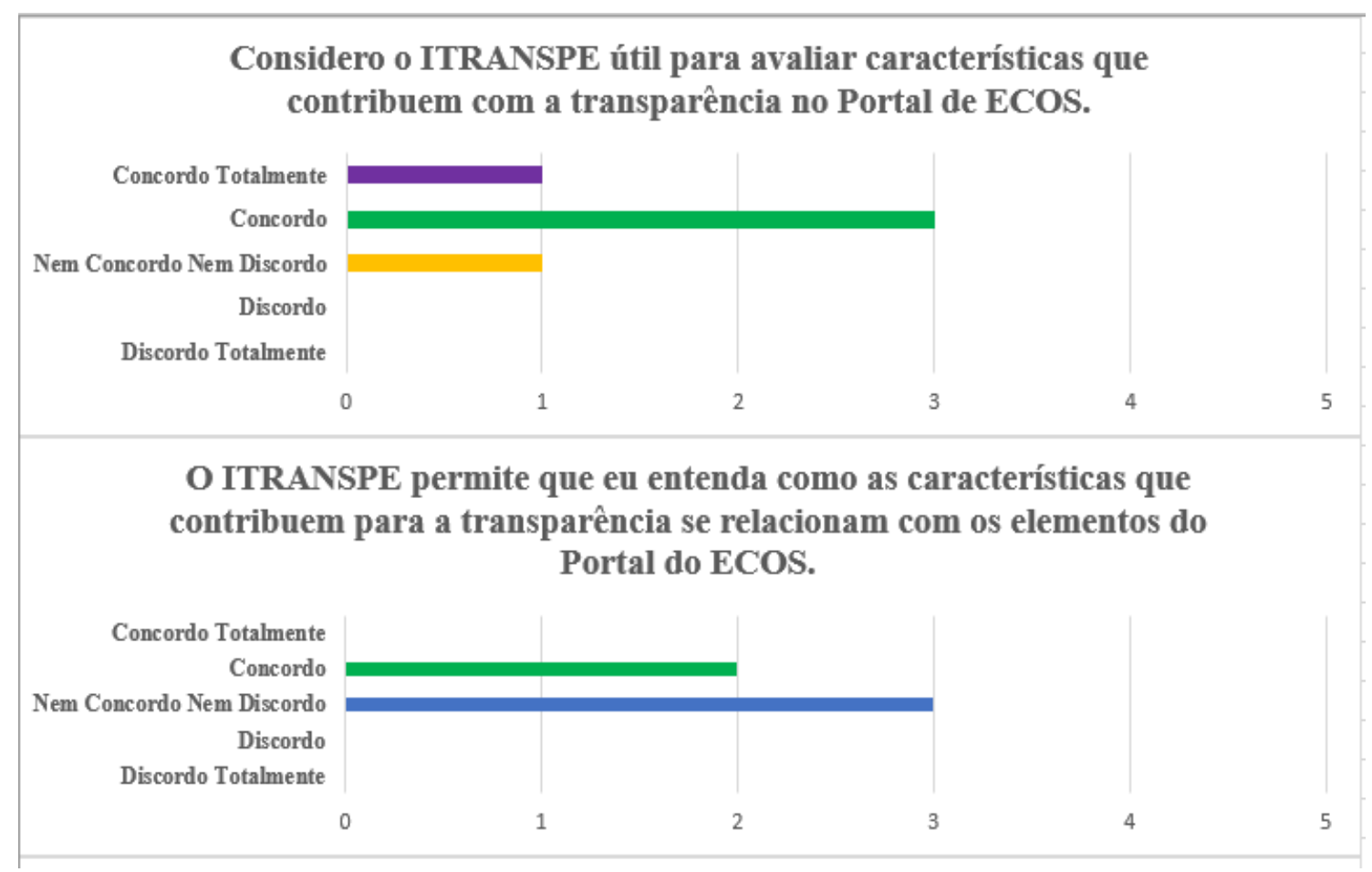

O ITRANSPE me ajudou a identificar oportunidades de melhorias no Portal do ECOS

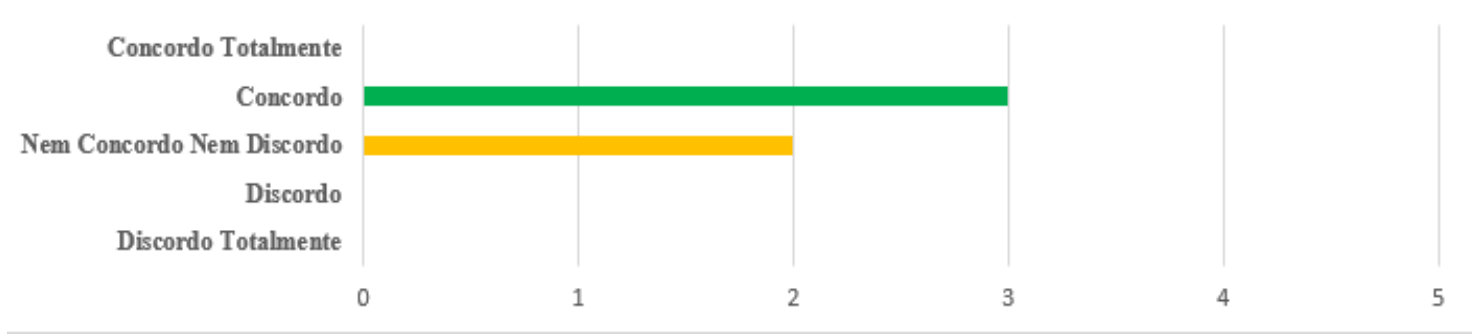

O ITRANSPE propõe soluções que melhoram a transparência de acordo com o objetivo do Portal do ECOS

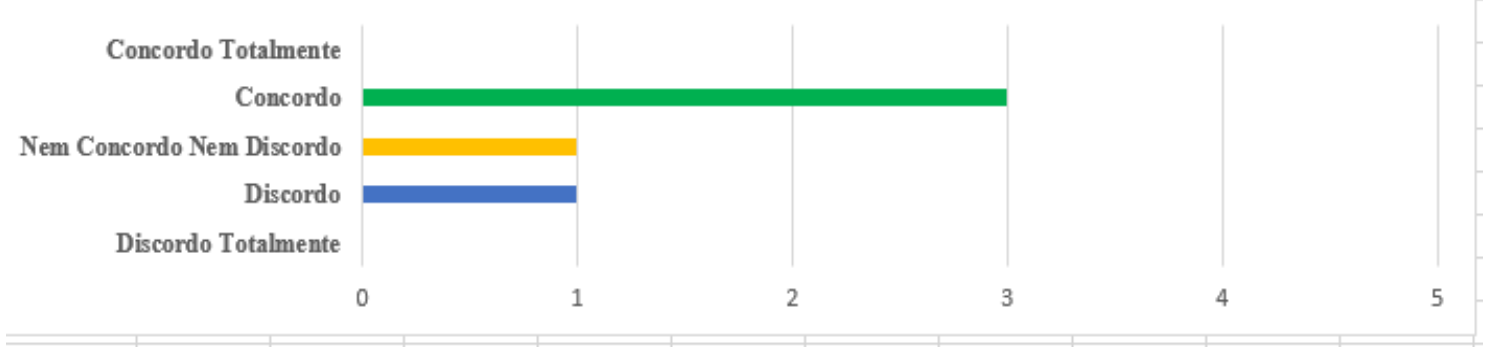

Figura 6. Resultados sobre Percepções de Utilidade do ITRANSPE (SPB)

\subsection{Análise e Discussão}

Apesar de 54 e-mails de convites enviados, apenas cinco desenvolvedores do Portal do SPB participaram do estudo. Dos dez convites enviados para desenvolvedores do Portal de Desenvolvimento dos Correios, apenas três participaram do estudo. No entanto, os 
comentários dos participantes foram bastante relevantes e as respostas contribuíram para a construção da versão final do ITRANSPE. A dificuldade de obter participantes talvez se deva ao fato do pesquisador ter obtido a lista de nomes de endereços na Internet, exposto na Seção 6.4, conforme recomendação de um participante do ECOS SPB. Dessa forma, não havia garantia que esses e-mails ainda estavam sendo usados (e.g., a esposa de um dos participantes informou que ele tinha falecido). Apesar disso, recebemos cinco respostas com comentários e considerações para a conclusão do estudo.

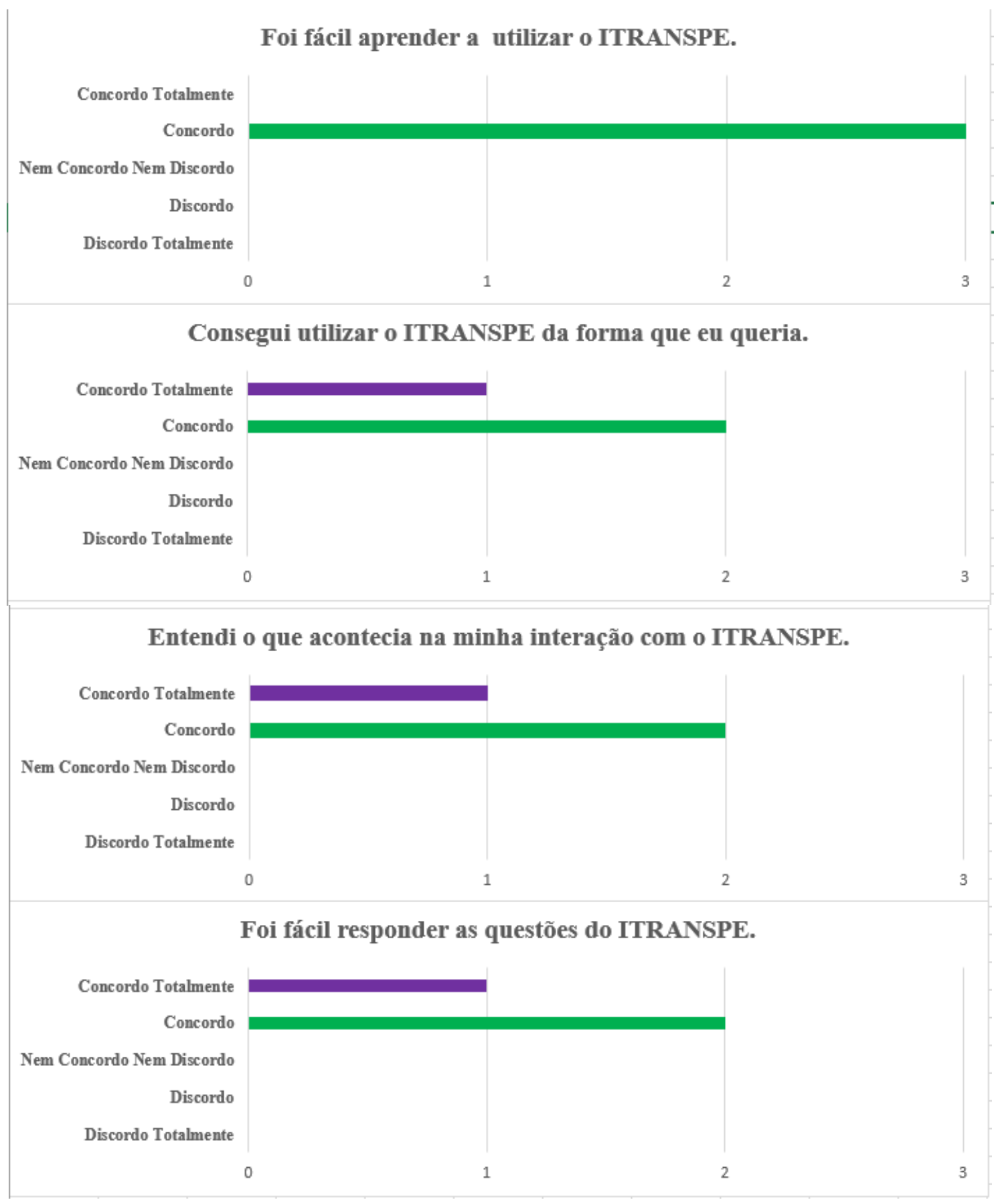

Figura 7. Resultado sobre Percepções de Facilidade de Uso do ITRANSPE (Correios) 


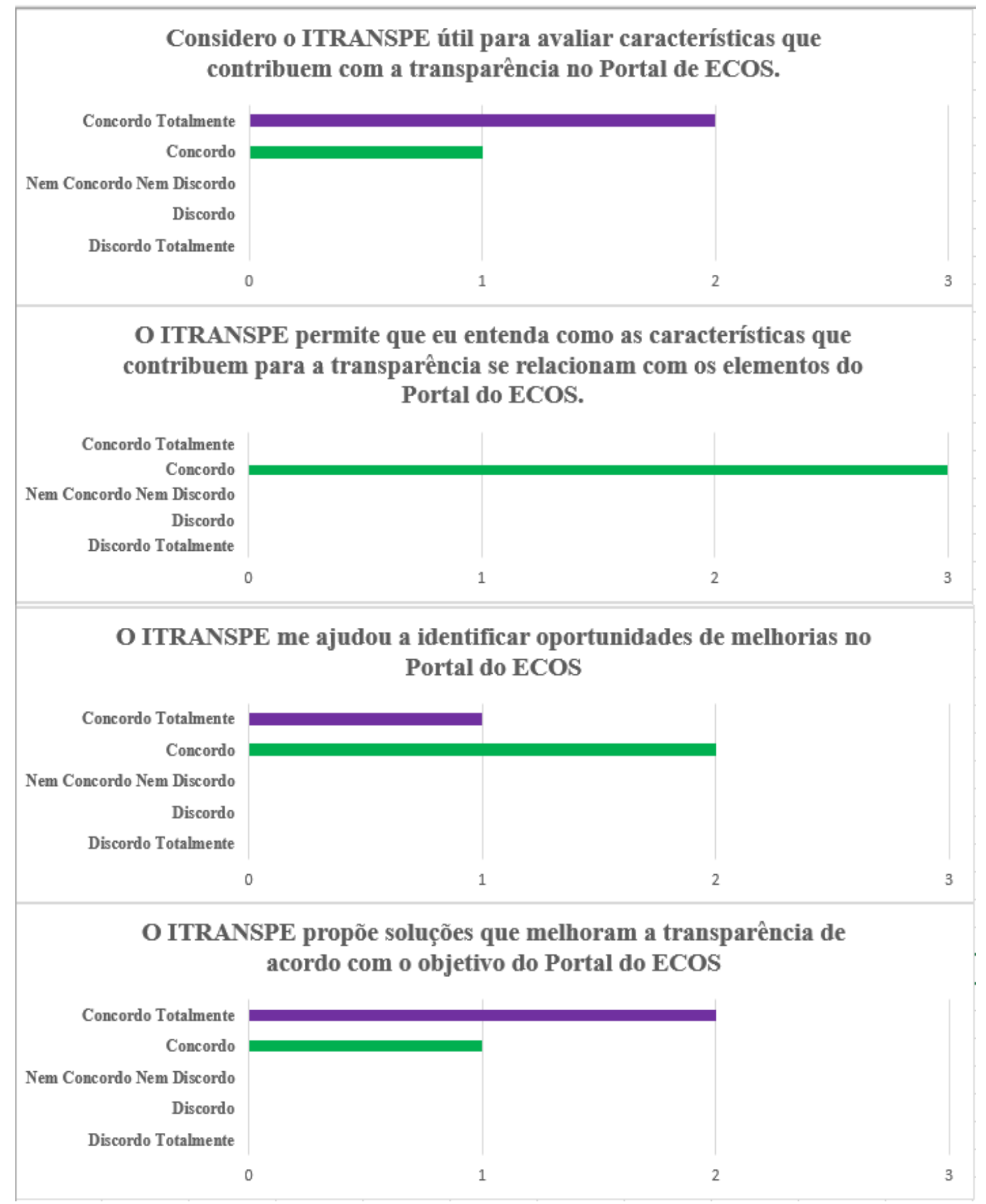

Figura 8. Resultados sobre Percepções de Utilidade do ITRANSPE (Correios)

Por sua vez, apesar de um dos pesquisadores trabalhar na empresa do ECOS Correios, sete desenvolvedores que foram convidados não manifestaram interesse de responder, conforme a descentralização do desenvolvimento de software existente na organização. Esses desenvolvedores eram de outros estados, o que pode ter causado dificuldade de acesso pessoal, apesar de terem sido enviados e-mails e efetuados contatos telefônicos. Dos três participantes que responderam, dois trabalham no Estado do Rio de Janeiro e um no Estado de São Paulo. Esses participantes agregaram valor ao estudo, opinando sobre características importantes que contribuem para a transparência, como 
auditabilidade e informativo, bem como com considerações sobre o ITRANSPE (não observaram pontos negativos).

Analisando as repostas obtidas sobre os dois portais, percebeu-se que todos os participantes conseguiram responder a todas as questões propostas. Cinco deles ficaram satisfeitos com as sugestões de melhorias, sendo três do ECOS Correios e dois do ECOS SPB. Quanto ao impacto no seu trabalho a partir do uso das sugestões apresentadas, três do ECOS Correios e três do ECOS SPB responderam que perceberam ganhos com o uso do ITRANSPE, o que pode indicar que o instrumento pode contribuir para a avaliação das características da transparência.

Sobre as questões relativas à facilidade de uso do ITRANSPE, avaliou-se a concordância sobre quatro itens. A maioria dos participantes do ECOS SPB e todos do ECOS Correios consideraram que foi fácil aprender a utilizar o ITRANSPE, que conseguiram utilizá-lo da forma que queriam, que entendiam a iteração com instrumento $\mathrm{e}$, por último, que foi fácil responder às suas questões. Esse resultado inicial pode indicar que o ITRANSPE é de fácil utilização, não requerendo muito treinamento para o seu uso.

Acerca das questões referentes à utilidade do ITRANSPE, também se avaliou a concordância sobre quatro itens. Similarmente, a maioria dos participantes do ECOS SPB e dois do ECOS Correios concordaram (um concordou totalmente) que o ITRANSPE é útil para avaliar características que contribuem com a transparência e que permite entender como elas se relacionam com o portal. Além disso, os participantes informaram que o instrumento ajudou a identificar oportunidades de melhoria e que propõe soluções que apoiam a transparência de acordo com o objetivo do portal. Com base nesses resultados, pode-se depreender que o ITRANSPE parece ser útil para avaliação e recomendação de melhorias na transparência em portais de ECOS.

Por fim, fez-se uma análise dos comentários e das sugestões colhidas nesse estudo e se construiu a versão final do ITRANSPE. Nessa nova versão, acrescentou-se uma aba que apresenta um relatório geral de sugestões das características não aplicadas ou aplicadas parcialmente (por característica). As sugestões de cada característica também ficaram em uma aba do instrumento. Além disso, alterou-se a forma de escolha das respostas para as questões, para que apenas uma resposta possa ser escolhida por questão.

Por fim, depois de analisar as respostas e os comentários dos participantes, há indicação inicial de que o ITRANSPE é viável, fácil de utilizar e útil para avaliar e pode contribuir para a transparência de portais de ECOS. Algumas oportunidades de melhorias foram identificadas, principalmente nas sugestões do instrumento. Analisando a utilidade, os participantes consideraram relevante o impacto da falta de transparência no portal de ECOS em suas atividades diárias. Isso reforça o prejuízo que a falta de transparência pode causar em um portal de ECOS e aumenta a importância do instrumento construído.

\subsection{Versão Final do ITRANSPE}

Com base nos resultados e na opinião dos desenvolvedores, o ITRANSPE foi aperfeiçoado para a versão final, na qual foi acrescentada uma aba onde consolidam-se as sugestões que contribuem para a transparência, essa aba está demonstrada na Figura 9. Na Figura 10, são mostradas as primeiras questões do ITRANSPE sobre a característica acessibilidade. A versão final do instrumento está disponível em um arquivo no link: https://drive.google.com/file/d/1 ffcVMmx8sYsPEC0R9b0gEygUL3dwYhx/view?usp =sharing. 
Relatório da Avaliação da Transparência em Portais de Ecossistemas de Software

\section{Acessibilidade}

Proposta de Melhoria: Identifique o browser que existe a alteração da interface, faça a modificação que corrija essa alteração. Proposta de Melhoria: Busque um nome mais específico com a proposta do Portal, a fim de que seja lembrado com mais facilidade

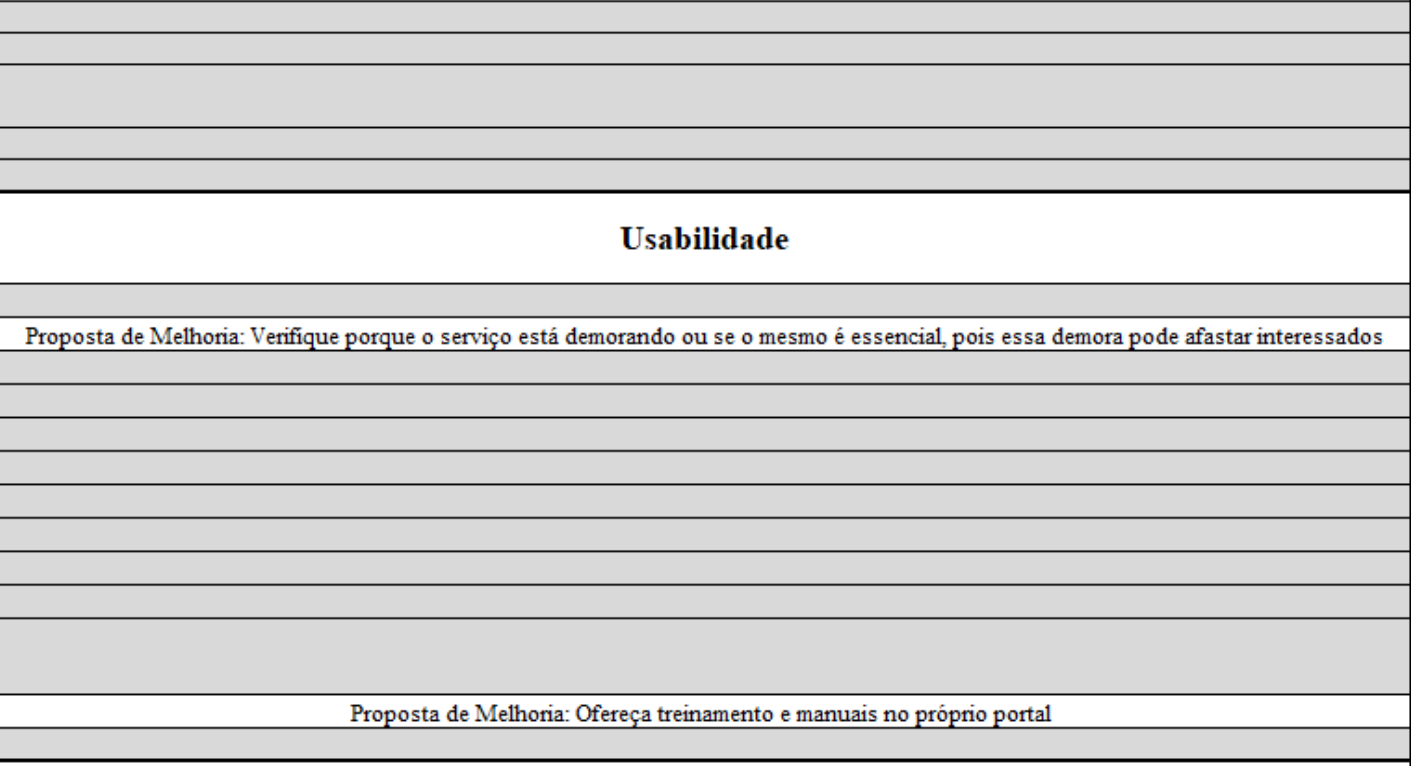

Figura 9. Relatório do ITRANSPE

\section{Instrumento para Avaliação e Sugestões de Mecanismos de} Transparência em Portais de Ecossistemas de Software

\section{Acessibilidade: Capacidade de Acesso}

Portabilidade: Capacidade do Portal de se apresentar em diferentes browsers

Questão 1: O Portal pode ser acessado por diferentes browsers, com a adequação da interface do Portal nos navegadores?

- Exemplo: O Portal do Software Público Brasileiro(https://softwarepublico.gov.br/social) pode ser acessado via Mozilla Firefox, Google Chrome, Microsoft Edge etc...

- Objetivo: Investigar se o Portal está preparado para ser acessado por qualquer browser, seja através de plugins ou outras tecnologias

- Justificativa: Garantir a portabilidade em diferentes browsers para facilitar o acesso aos conteúdos oferecidos pelo Portal. Evitando a alteração

da sua interface

Ø Dica: São browsers mais amplamente utilizados: Google Chrome, Mozilla Firefox, Internet Explorer, Microsoft Edge, Safari e Opera.

Parcislmente Aplics - Proposta de Melhoria: Identifique o browser que existe a alteração da interface, faça a modificação que corrija essa alteração.

Publicidade: Capacidade de tornar-se público aos desenvolvedores

Questão 1: O endereço do portal (URL) é direto, intuitivo e fácil de ser lembrado?

- Exemplo: A URL do Portal da Apple é: wwww.apple.com.

- Objetivo: Investigar se a URL do Portal é fácil de ser lembrada.

- Justificativa: Garantir que o Portal seja acessado através de uma URL adequada, intuitiva e direta, facilitando o acesso às informações serviços, uma vez que o endereço pode ser facilmente lembrado pelos desenvolvedores.

$\emptyset$ Dica: Exemplo de URL ruim: wwww.r-project.org, não sendo intuitivo também.

Parcislmente Aplics - Proposta de Melhoria: Busque um nome mais especifico com a proposta do Portal, a fim de que seja lembrado com mais facilidade

Figura 10. Avaliação de acessibilidade do ITRANSPE 


\section{Conclusão}

Esse trabalho teve como objetivo a construção de um instrumento que permita avaliar mecanismos de transparência em portais de ECOS, denominado ITRANSPE, que visa apoiar a busca por informações por parte dos desenvolvedores que os utilizam. É importante ressaltar que a transparência em ECOS ainda é pouco explorada pela literatura. Para contribuir nesse sentido, a concepção do ITRANSPE foi embasada pelos resultados de um estudo exploratório e de um mapeamento sistemático, partindo do questionário para avaliação de transparência em sites de Cappelli (2009) e Carvalho et al. (2017). Um artefato inicial criado foi submetido a um estudo com dez especialistas a fim de verificar a relevância das questões que contemplava. Após o estudo com especialistas, construiuse a primeira versão do ITRANSPE, que foi disponibilizado para desenvolvedores por meio de um novo estudo para verificar a percepção de facilidade de uso e de utilidade. Para isso, os desenvolvedores utilizaram o ITRANSPE em determinado portal de ECOS, buscando responder às perguntas do questionário e opinando sobre as sugestões do instrumento. Com base nesse estudo, evoluiu-se para a versão final do ITRANSPE.

A contribuição deste trabalho é buscar a criação de um instrumento que permita avaliar de forma estruturada as características que contribuem para a transparência em portais de ECOS e propor sugestões que auxiliem o desenvolvimento dessas características, com base nas necessidades dos desenvolvedores. Devido ao caráter genérico do instrumento, o ITRANSPE pode ser usado em qualquer portal de ECOS que se deseje avaliar a transparência. Além disso, o estudo avança nas pesquisas que exploram transparência em ECOS, contribuindo para agenda de pesquisa seminal no assunto proposta por Santos et al. (2016). No entanto, o ITRANSPE possui algumas limitações, como falta de configuração do contexto do portal do ECOS que será avaliado a priori, para que haja filtragem de algumas características e/ou questões e questão de melhoria do design do instrumento que é operacionalizado por meio de planilha eletrônica.

As limitações identificadas para este trabalho são: (1) no mapeamento sistemático, encontrou-se uma quantidade pequena de artigos que abordassem transparência em ECOS e, além disso, incialmente, o termo "transparent*" não foi considerado na string (após nova análise de trabalhos com este termo no context de ECOS, não foram identificados trabalhos que contribuíssem para responder as SubQs); (2) a seleção dos especialistas que participaram do estudo para validar o questionário teve participação de brasileiros, o que pode limitar a pesquisa ao cenário nacional; e (3) o número de participantes que quiseram participar do estudo de viabilidade não foi elevado pois, apesar de terem sido enviados 59 e-mails para desenvolvedores do ECOS SPB, replicados duas vezes, apenas cinco participaram do estudo; por sua vez, no ECOS Correios, dois desenvolvedores já tinham participado do estudo piloto e, dos outros dez convidados, apenas três aceitaram participar do estudo, o que impede a generalização dos resultados. Não se buscou nesse estudo identificar um perfil de avaliador de transparência nem relacionar as características da transparência com aspectos da interação humanocomputador (IHC).

Como trabalhos futuros, algumas oportunidades de pesquisa podem ser citadas, tais como: investigar a transparência na arquitetura de ECOS; investigar como a transparência pode influenciar a qualidade e a saúde do ECOS; avaliar a transparência nos portais em outras perspectivas, por exemplo a perspectiva do usuário; evoluir o ITRANSPE, principalmente no que se refere às sugestões de melhorias para as 
características que contribuem para a transparência; avaliar casos de portais de ECOS sensíveis ao negócio da organização, por exemplo, quando o grau de transparência de determinadas características não é requerido em sua totalidade (ou pode até mesmo ter como meta não possuir tal característica); e aplicar o ITRANSPE em um portal de ECOS e acompanhar a sua influência na saúde e na qualidade do ECOS.

\section{Referências}

Barbosa, O.; Santos, R. P.; Alves, C.; Werner, C.; Jansen, S. (2013) "A Systematic Mapping Study on Software Ecosystems through a Three-dimensional Perspective". In Jansen, S. et al. (eds.) Software Ecosystems: Analyzing and Managing Business Networks in the Software Industry. Edward Elgar Publishing, pp. 59-84.

Basili, V. R.; Caldiera, G.; Rombach, H. D. (1994) "The goal question metric approach". Encyclopedia of Software Engineering, v. 1, pp. 528-532.

Bogart, C.; Kastner, C.; Herbsleb, J.; Thung, F. (2016) "How to Break an API: Cost Negotiation and Community Values in Three Software Ecosystems". In: Proceedings of the XXIV ACM SIGSOFT International Symposium on Foundations of Software Engineering Seattle, USA, pp. 109-120.

Bosch, J. (2009) "From Software Products Line to Software Ecosystem". In: Proceedings of 13th International Software Product Line Conference (SPLC), San Francisco, USA, pp. 1-10.

Campbell, P.; Ahmed, F. (2010) "A Three-dimensional View of Software Ecosystems". In: Proceedings of the IV European Conference on Software Architecture Workshops, Copenhagen, Denmark, pp. 81-84.

Cappelli, C. (2009) "Uma Abordagem para Transparência em Processos Organizacionais Utilizando Aspectos". Tese de Doutorado, PUC-Rio, Rio de Janeiro, Brasil.

Cappelli, C.; Engiel, P.; Leite, J.; Nunes V.; Tanaka, A.; Araujo, R.; Santos, G.; Benjamin K.; Moraes, M. (2013) "Construção do modelo de Maturidade em Transparência Organizacional". In: Anais do WTRANS13 - Workshop de Transparência em Sistemas, Brasília, Brasil.

Cartlidge, A.; Hanna, A.; Rudd, C.; Macfarlane, I.; Windebank, J.; Rance, S. (2008) "An Introductory Overview of ITIL 2008 V.3".

Carvalho, L.; Cappelli, C.; Santoro, F. (2017) "Transparência de Software Centrada na Análise de Sites". In: Anais do XXXVII Congresso da Sociedade Brasileira de Computação, WTRANS, São Paulo, Brasil, pp. 378-387.

Castro, S.; Mens, K.; Moura, P. (2013) "Logic Objects: Enabling logic programing in Java through Linguistic Symbiosis". In: Proceedings of the XV International Symposium on Practical Aspects of Declarative Languages (PADL), Rome, Italy, pp. 26-42.

Cataldo, M.; Herbsleb, J. (2010) "Architecting in Software Ecosystems: Interface Translucence as an Enabler for Scalable Collaboration". In: Proceedings of the IV European Conference on Software Architecture Workshops, Copenhagen, Denmark, pp. 65-72. 
Cruz, W.; Maciel, C.; Castilho, F.; Girata, N. (2016) "Um Método Quantitativo para Avaliar a Adoção de Dados Abertos nos Tribunais de Contas do Brasil". iSys Revista Brasileira de Sistemas de Informação 9(1):33-57

Davis, F. (1993) "User Acceptance of Information Technology: System Characteristics, User Perceptions and Behavioral Impacts". International Journal of Man-Machine Studies 38(3):475-487.

Fahl, S.; Dechand, S.; Perl, H.; Fisher, F.; Smrcek, J.; Smith, M. (2014) "Hey NSA: Stay Away from My Market! Future Proofing App Markets Against Powerful Attackers". In: Proceedings of the ACM SIGSAC Conference on Computer and Communications Security, Arizona, USA, pp. 1143-1155.

Franco-Bedoya, O.; Ammeller, D.; Costal; Franch, X. (2014) "Queso a quality model for open source software ecosystems". In: Proceedings of the IX International Conference of the Software Engineering and Applications (ICSOFT-EA), Vienna, Austria, pp. 209-221.

Germano, C.; Takaoka, H. (2012) "Uma Análise das Dimensões da Qualidade de Dados Abertos em Projetos de Dados Governamentais Abertos". In: Anais do Congresso CONSAD de Gestão Pública, Brasília, Brasil, pp. 1-21.

Goyal, R.; Ferreira, G.; Kastner, C.; Herbsleb, J. (2017) "Identifying Unusual Commits on GitHub". Proceeding Journal of Software: Evaluation and Process 30(1):1-16.

Gutwin, C.; Penner, R.; Schnneider, K. (2004) "Group awareness in distributed software development". In: Proceedings of the ACM CSCW, Chicago, USA, pp. 6-10.

Herbsleb, J.; Kastner, J.; Bogart, C. (2016) "Intelligently Transparent Software Ecosystems". IEEE Software 33(1):89-96.

Holzner, B.; Holzner, L. (2008) "Transparency in Global Change: The Vanguard of the Open Society". American Journal of Sociology 114(1):267-269.

Jansen, S.; Brinkkemper, S.; Finkelstein, A. (2009) "Introduction to the proceeding of the First International Workshop on Software Ecosystems". In: Proceedings of the First International Workshop on Software Ecosystems, Falls Church, USA, pp. 1-2.

Jansen, S.; Cusumano, M. (2012) "Defining Software Ecosystems: A Survey of Software Ecosystems and Ecosystem". In: Proceedings of the IV International Workshop on Software Ecosystems, Cambridge, USA, pp. 41-58.

Jansen, S.; Brinkkemper, S.; Souer, J.; Luinenburg, L. (2012) "Shades of Gray: Opening up a Software Producing Organization with the Open Software Enterprise Model". Journal of Systems and Software 85(7):1495-1510.

Jansen, S.; Cusumano, M.; Brinkkemper, S. (2013) "Software Ecosystems: Analyzing and Managing Business Networks in the Software Industry". Edward Elgar Publishing.

Kitchenham, B.; Charters, S. (2007) "Guidelines for Performing Systematic Literature Reviews in Software Engineering". Tech. Rep. EBSE-2007-01, Keele University.

Knauss, E.; Damian, D.; Knauss, A.; Borici, A. (2014) "Openness and Requirement: Opportunities and tradeoffs in software ecosystems". In: Proceedings of the XXII International Requirements Engineering Conference, Essen, Germany. 
Knauss, E.; Yussuf, A.; Blincoe, K.; Damian, D.; Knauss, A. (2018) "Continuous Clarification and Emergent Requirements Flows in Open-Commercial Software Ecosystems". Requirements Engineering 33(1):97-117.

Kruize, J.; Wolfert, S.; Goense, D.; Scholthen, H.; Beulens, A.; Veenstra, T. (2014) "Integrating ICT applications for farm business collaboration processes using FI Space". In: Proceedings of the Annual SRII Global Conference, San Jose, USA. pp. 232-240.

Leite, J.; Cappelli, C. (2010) "Software Transparency". Business \& Information Systems Engineering 2(2010):127-139.

Linãker, J.; Wnuk, K. (2016) "Requirements Analysis and Management for Benefiting Openness". In: Proceedings of the XXIV International Requirements Engineering Conference Workshops (REW), Beijing, China, pp. 344-349.

Lord, K. (2007) "The Perils and Promise of Global Transparency - Why the Information Revolution May Not Lead to Security, Democracy, or Peace". SUNY series in Global Politics, State University of New York Press, 2007.

Manikas, K.; Hansen, K. (2013) "Software Ecosystems - A Systematic Literature Review". The Journal of Systems and Software 86(5):1294-1306.

Meireles, A. (2018) "Um Instrumento para Avaliação de Transparência em Portais de Ecossistemas de Software". Dissertação, PPGI/UNIRIO, Rio de Janeiro, Brasil.

Meireles, A.; Santos R.; Cappelli, C. (2017a) "Explorando o Conceito de Transparência em Portais de Ecossistemas de Software". In: Extended Proceedings of the 16th Brazilian Symposium on Human Factors in Computing Systems, Joinville, Brasil, v. B, pp. 84-85.

Meireles, A.; Santos R.; Cappelli, C. (2017b) "Construindo um Questionário para Avaliar Transparência em Portais de Ecossistemas de Software". In: Anais do VIII Workshop sobre Aspectos da Interação Humano-Computador na Web Social, Joinville, Brasil, pp. 25-35.

Molder, J.; Lier, B.; Jansen, S. (2011) "Clopenness of Systems: The Interwoven Nature of Ecosystems". In: Proceedings of the III International Workshop on Software Ecosystems, Brussels, Belgium, pp. 52-64.

Nitze, A.; Schmietendorf, A.; Dumke, R. (2014) "An analogy-based effort estimation approach for mobile application development projects". In: Proceedings of the International Conference on Software Process and Product Measurement, Rotterdam, Netherlands, pp. 99-103.

Recker, J. (2012) "Scientific research in information systems: a beginner's guide". Springer Science \& Business Media.

Santos, R.; Cappelli, C.; Maciel, C.; Leite, J. (2016) "Transparência em Ecossistemas de Software". In: Anais do X Workshop de Desenvolvimento Distribuído de Software, Ecossistemas de Software e Sistemas-de-Sistemas, Maringá, Brasil, pp. 75-79.

Schnackenberg, A.; Tomlinson, C. (2014) "Organizational Transparency - A New Perspective on Managing Trust in Organization - Stakeholder Relationships". The Journal Management 42(7):1784-1810 
Vegendla, A.; Duc, A.; Gao, S.; Sindre, G. (2018) "A Systematic Mapping Study on Requirements Engineering in Software Ecosystems". Journal of Information Technology Research 11(1).

Wnuk, K.; Runeson, P.; Lantz, M.; Weijden, O. (2014) "Bridges and Barries to HardwareDependent Software Ecosystem Participation - A Case Study". Information and Software Technology 56(11):1439-1507.

\section{Apêndice I - Lista dos Artigos Analisados}

\begin{tabular}{|c|c|}
\hline ID & Referência \\
\hline 01 & $\begin{array}{l}\text { Vegendla, A.; Duc, A.; Gao, S.; Sindre, G. (2018) "A Systematic Mapping Study on Requirements } \\
\text { Engineering in Software Ecosystems". Journal of Information Technology Research 11(1). }\end{array}$ \\
\hline 02 & $\begin{array}{l}\text { Knauss, E.; Yussuf, A.; Blincoe, K.; Damian, D.; Knauss, A. (2018) "Continuous Clarification and } \\
\text { Emergent Requirements Flows in Open-Commercial Software Ecosystems". Requirements } \\
\text { Engineering 33(1):97-117. }\end{array}$ \\
\hline 03 & $\begin{array}{l}\text { Meireles, A.; Santos R.; Cappelli, C. (2017b) "Construindo um Questionário para Avaliar } \\
\text { Transparência em Portais de Ecossistemas de Software". In: Anais do VIII Workshop sobre } \\
\text { Aspectos da Interação Humano-Computador na Web Social, Joinville, Brasil, pp. 25-35. }\end{array}$ \\
\hline 04 & $\begin{array}{l}\text { Goyal, R.; Ferreira, G.; Kastner, C.; Herbsleb, J. (2017) "Identifying Unusual Commits on } \\
\text { GitHub". Proceeding Journal of Software: Evaluation and Process 30(1):1-16. }\end{array}$ \\
\hline 05 & $\begin{array}{l}\text { Bogart, C.; Kastner, C.; Herbsleb, J.; Thung, F. (2016) "How to Break an API: Cost Negotiation } \\
\text { and Community Values in Three Software Ecosystems". In: Proceedings of the XXIV ACM } \\
\text { SIGSOFT International Symposium on Foundations of Software Engineering Seattle, USA, pp. } \\
109-120 \text {. }\end{array}$ \\
\hline 06 & $\begin{array}{l}\text { Herbsleb, J.; Kastner, J.; Bogart, C. (2016) "Intelligently Transparent Software Ecosystems". IEEE } \\
\text { Software 33(1):89-96. }\end{array}$ \\
\hline 07 & $\begin{array}{l}\text { Linãker, J.; Wnuk, K. (2016) "Requirements Analysis and Management for Benefiting Openness". } \\
\text { In: Proceedings of the XXIV International Requirements Engineering Conference Workshops } \\
\text { (REW), Beijing, China, pp. 344-349. }\end{array}$ \\
\hline 08 & $\begin{array}{l}\text { Fahl, S.; Dechand, S.; Perl, H.; Fisher, F.; Smrcek, J.; Smith, M. (2014) "Hey NSA: Stay Away } \\
\text { from My Market! Future Proofing App Markets Against Powerful Attackers". In: Proceedings of } \\
\text { the ACM SIGSAC Conference on Computer and Communications Security, Arizona, USA, pp. } \\
\text { 1143-1155. }\end{array}$ \\
\hline 09 & $\begin{array}{l}\text { Knauss, E.; Damian, D.; Knauss, A.; Borici, A. (2014) "Openness and Requirement: Opportunities } \\
\text { and tradeoffs in software ecosystems". In: Proceedings of the XXII International Requirements } \\
\text { Engineering Conference, Essen, Germany. }\end{array}$ \\
\hline 10 & $\begin{array}{l}\text { Jansen, S.; Brinkkemper, S.; Souer, J.; Luinenburg, L. (2012) "Shades of Gray: Opening up a } \\
\text { Software Producing Organization with the Open Software Enterprise Model". Journal of Systems } \\
\text { and Software 85(7):1495-1510. }\end{array}$ \\
\hline 11 & $\begin{array}{l}\text { Molder, J.; Lier, B.; Jansen, S. (2011) "Clopenness of Systems: The Interwoven Nature of } \\
\text { Ecosystems". In: Proceedings of the III International Workshop on Software Ecosystems, Brussels, } \\
\text { Belgium, pp. 52-64. }\end{array}$ \\
\hline 12 & $\begin{array}{l}\text { Cataldo, M.; Herbsleb, J. (2010) "Architecting in Software Ecosystems: Interface Translucence as } \\
\text { an Enabler for Scalable Collaboration". In: Proceedings of the IV European Conference on } \\
\text { Software Architecture Workshops, Copenhagen, Denmark, pp. 65-72. }\end{array}$ \\
\hline
\end{tabular}

